\title{
R-BPM: Uma Metodologia para Gerenciamento de Processos de Negócios Consciente dos Riscos
}

\author{
Fábio da Silva Ferreira ${ }^{1}$, Carina Frota Alves $^{2}$, Rosa Candida Cavalcanti ${ }^{3}$ \\ ${ }^{1}$ Instituto Federal do Sudeste de Minas Gerais - Campus Barbacena (IF Sudeste MG) \\ ${ }^{2}$ Centro de Informática - Universidade Federal de Pernambuco (CIn - UFPE) \\ ${ }^{3}$ Faculdade dos Guararapes (FG) \\ fabio.ferreiradifsudestemg.edu.br, cfa@cin.ufpe.br, \\ rosa.candida@faculdadeguararapes.edu.br
}

\begin{abstract}
In search for agility, economy and quality in their processes, an increasing number of companies have adopted techniques of Business Process Management (BPM). However, even when managed, processes may face risks that can cause strong impact on the organization's goals if these risks are not managed appropriately. This paper aimed to construct and evaluate a methodology to manage risks of business processes integrated with the BPM lifecycle. The methodology, called R-BPM, is inspired by the COSO (Committee of Sponsoring Organizations of the Treadway Commission) risk management structure and was built following the Design Science Research strategy. To evaluate the methodology, we conducted a case study in an experienced organization in BPM. The artifacts were assessed through focus groups and surveys with the organization's experts. The results showed that the methodology allows the activities related to risk management to be implemented together with the BPM lifecycle. The integration between risk and business process activities optimizes resources and ensures a holistic view of business processes and their associated risks.
\end{abstract}

Resumo. Na busca por agilidade, economia e qualidade em seus processos, um número crescente de empresas tem adotado técnicas de Gerenciamento de Processos de Negócios (Business Process Management-BPM). No entanto, mesmo gerenciados, os processos podem enfrentar riscos que podem causar forte impacto sobre os objetivos da organização se esses riscos não forem gerenciados de forma apropriada. Este artigo tem como objetivo construir e avaliar uma metodologia para realizar o gerenciamento de riscos em processos de negócios de forma integrada com o ciclo de vida BPM. A metodologia, chamada R-BPM, é inspirada na estrutura de gerenciamento de riscos do COSO (Committee of Sponsoring Organizations of the Treadway Commission) e foi construída através da estratégia de Design Science Research. Para avaliar a metodologia foi realizado um estudo de caso em uma organização experiente em BPM. Os artefatos foram avaliados através de grupos focais e surveys com especialistas da organização. Os resultados mostraram que a metodologia permite que as atividades relacionadas à gestão de riscos sejam executadas em conjunto com o ciclo de vida BPM. A integração entre atividades de riscos e processos de negócios otimiza recursos e fornece uma visão holística dos processos de negócios e seus riscos associados.

FERREIRA, F. S.; ALVES, C. F.; CAVALCANTI, R. C.

R-BPM: Uma Metodologia para Gerenciamento de Processos de Negócios Consciente dos Riscos

isys | Revista Brasileira de Sistemas de Informação, Rio de Janeiro, vol. 9, No. 4, pp. 05-37, 2016 


\section{Introdução}

O aumento da competividade e das exigências impostas às empresas e organizações tem aumentado a demanda por melhores serviços tanto na área pública quanto na privada, levando a um aumento de cobrança dentro das organizações por maior eficiência e eficácia na execução dos seus processos de negócio. Com a utilização de técnicas e conceitos da abordagem de Gerenciamento de Processos de Negócios (do original em inglês: Business Process Management - BPM) é possível que uma organização torne seus processos mais eficientes, com maior precisão, rapidez, flexibilidade e qualidade [HAMMER, 2010].

No entanto, mesmo tendo seus processos gerenciados e já usufruindo dos benefícios obtidos com BPM, as organizações podem enfrentar incertezas nas atividades de seus processos que podem causar forte impacto sobre seus objetivos. Eventos adversos e impactos associados são comumente conhecidos como riscos. Qualquer atividade organizacional está sujeita a ter riscos, tais como: prazos não cumpridos, custos excedendo o que foi planejado, fraudes, falhas tecnológicas, desastres naturais, entre outros. A interrupção das operações dos negócios devido à concretização de algum risco em seus processos pode se tornar uma grande ameaça para a organização e afetar seus objetivos [HAGGAG, KHEDR e MONTASSER, 2015]. Uma vez que os processos de negócios de uma organização estão expostos a diferentes tipos de riscos o tempo todo, é necessário um mecanismo que permita tratá-los. Tamanha é a importância do gerenciamento de riscos em processos de negócios que a integração desses dois campos tradicionalmente separados tem sido tema de pesquisas frequente nos últimos anos e tratada pelos pesquisadores como Gerenciamento de Processos de Negócios Consciente dos Riscos (do original em inglês: Risk-Aware Business Process Management - R-BPM) [HAGGAG, KHEDR e MONTASSER, 2015], [SURIADI et al., 2014].

No entanto, as atividades de gerenciamento de riscos propostas nessas pesquisas são aplicadas apenas a algumas fases do ciclo de vida BPM e, em muitos casos, não são realizadas todas as atividades necessárias ao gerenciamento de riscos. Sienou et al. (2010), Betz et al. (2011), Weiss e Winkelmann (2011), Cope et al. (2010) e Rotaru et al. (2011), por exemplo, propõem para a fase de modelagem do processo, a definição de artefatos para comunicar os riscos através de modelos de processos de negócios. Jallow et al. (2007) e Fenz e Neubauer (2009) propõem técnicas para analisar e avaliar os riscos com relação à probabilidade de ocorrência e impacto também nas fases iniciais do ciclo de vida BPM. Conforti et al. (2011) têm realizado pesquisas para identificar riscos durante a fase de execução dos processos de negócios e Wickbold et al. (2011) e Jans et al. (2011) propõem uma análise dos riscos com base nos registros coletados durante a execução dos processos. Já o trabalho de Haggag, Khedr e Montasser (2015) propõe um modelo para identificar riscos em todas as fases do ciclo de vida BPM. No entanto esse último trabalho apenas auxilia na identificação de riscos, outras atividades como análise, avaliação, monitoramento e controle dos riscos não são abordadas.

Baldam (2014) destaca que é necessário gerenciar os riscos em todas as fases do ciclo de vida BPM, pois toda ação possui diversos riscos embutidos. Na fase de análise, por exemplo, é possível que uma atividade não seja modelada por causa do não envolvimento de alguma parte interessada. $\mathrm{Na}$ fase de desenho, podemos não conseguir alterar uma rotina de trabalho necessária para a melhoria do processo devido às 
resistências dos funcionários acostumados com uma forma de trabalho. Não obter indicadores de desempenho apropriados pode ser um risco durante a fase de monitoramento. Assim, não devemos esperar o risco ocorrer para tratá-lo, e nem tratá-lo de forma isolada das atividades de BPM. Devemos agir de forma proativa no sentido de minimizar o efeito e até mesmo eliminar ou tirar proveito do risco. Portanto, é extremamente importante que a organização saiba a quais riscos seus processos estão expostos e defina as melhores formas de tratá-los.

Assim, tendo como principal interesse gerenciar riscos em processos de negócios de forma integrada com o clico de vida BPM, este artigo pretende investigar as seguintes questões de pesquisa:

- (QP1): Quais são as abordagens existentes para gerenciar riscos de forma integrada com BPM e quais são as suas limitações?

- (QP2): Qual é o modelo de gerenciamento de riscos mais adequado para ser integrado com BPM?

- (QP3): Como gerenciar riscos em processos de negócios de forma integrada com o ciclo de vida BPM?

- (QP4): Quais são os principais benefícios em gerenciar riscos de processos de negócios de forma integrada com BPM?

O presente artigo propõe uma metodologia e uma ferramenta de apoio para gerenciar riscos em processos de negócios de forma integrada com o ciclo de vida BPM. A motivação para propor essa integração inclui os seguintes benefícios: economizar recursos, evitar retrabalhos, descentralizar a responsabilidade pelos riscos e fornecer melhores condições para os donos dos processos avaliá-los. Para a avaliação da metodologia, foi realizado um estudo de caso em uma organização experiente em BPM.

O restante deste trabalho está organizado da seguinte forma: A Seção 2 apresenta um referencial teórico necessário para um melhor entendimento do trabalho e discute os principais trabalhos relacionados. A Seção 3 apresenta o método de pesquisa adotado. A seção 4 apresenta a metodologia R-BPM. A Seção 5 apresenta o relato da execução do Estudo de Caso utilizado como parte integrante da estratégia de Design Science Reserch para avaliação da metodologia R-BPM, detalhando suas etapas e seus resultados e comparando-a com os trabalhos relacionados. Finalmente, a Seção 6 apresenta as conclusões e recomendações para trabalhos futuros.

\section{Referencial Teórico}

Esta seção tem como objetivo introduzir conceitos necessários para um melhor entendimento do trabalho proposto.

\subsection{Gerenciamento de Processos de Negócio (BPM)}

Para Davenport (1994), a maneira tradicional de melhorar qualquer forma de trabalho é tratá-lo como um processo. Um processo é um conjunto definido de atividades ou comportamentos executados por humanos ou máquinas para alcançar uma ou mais metas [ABPMP, 2013]. 
A disciplina de Gerenciamento de Processos de Negócios (BPM) é abordagem disciplinada para identificar, desenhar, executar, documentar, medir, monitorar, controlar e melhorar os processos de negócios visando alcançar resultados consistentes e alinhados com os objetivos estratégicos da organização [ABPMP, 2013]. O sucesso de BPM está ligado ao esforço de diminuir a necessidade de cumprir o papel hierárquico dos departamentos e adotar um enfoque mais horizontal.

\subsection{Ciclo de Vida BPM}

Existem diversos modelos propostos na literatura para orientar a gestão de processos de negócio, sendo que a maioria deles assume a forma cíclica baseada no modelo PDCA (do inglês: Plan, Do, Check, Act) com as atividades organizadas em fases e se repetindo a cada fase, por esta razão fala-se em ciclos de vida BPM [Baldam, 2014]. Este trabalho adota o ciclo de vida BPM da metodologia EBPM (do inglês: Easy Business Process Management) proposta por Oliveira (2014), pelo fato da metodologia ser de fácil utilização e voltada para organizações que estão iniciando ações em BPM.

O ciclo de vida proposto por Oliveira (2014) foi elaborado tendo como linha de base o Common body of knowledge (CBOK) da ABPMP (2013) e levando em consideração a análise de diversos ciclos apresentados na academia e na indústria. Ele é composto de seis fases que se relacionam, conforme apresentado na Figura 1:

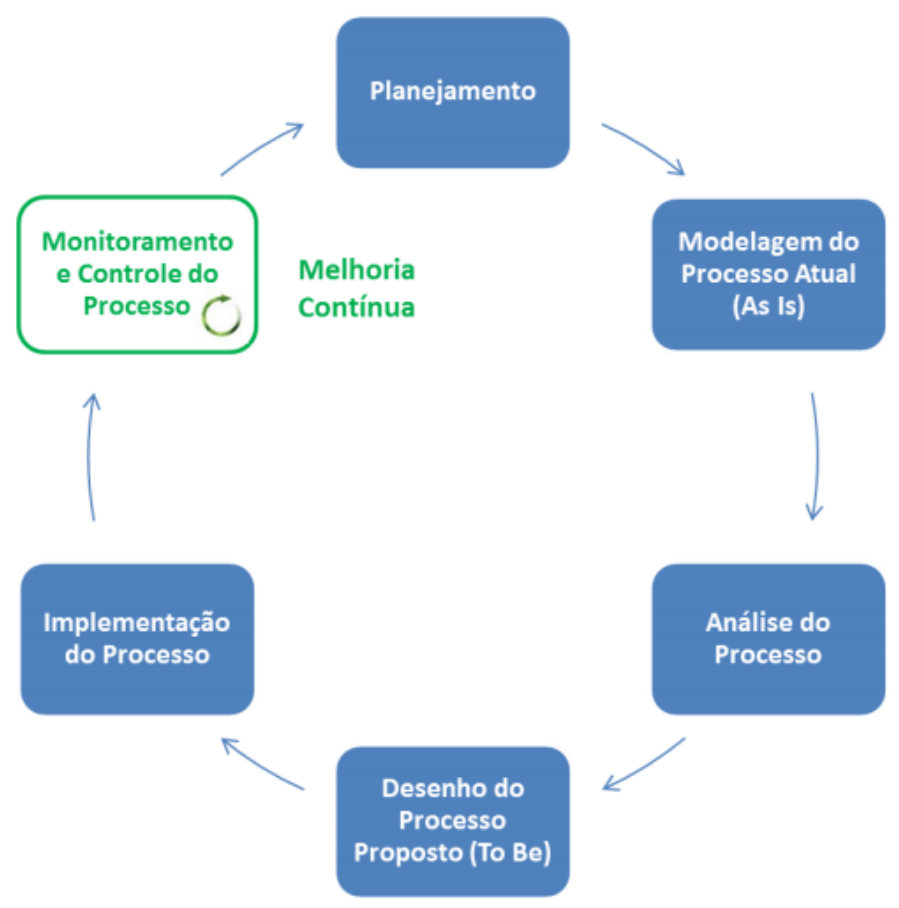

Figura 1. Ciclo de vida BPM - Fonte: Oliveira (2014)

As fases poderão ser executadas integralmente e na sequência apresentada ou, de acordo com a necessidade de cada projeto BPM, poderão ser simplificadas.

\subsection{Gerenciamento de Riscos}

De acordo com o COSO (2004), risco é a possibilidade de ocorrência de um evento que afeta de maneira adversa os objetivos da organização. A etimologia da palavra risco FERREIRA, F. S.; ALVES, C. F.; CAVALCANTI, R. C.

R-BPM: Uma Metodologia para Gerenciamento de Processos de Negócios Consciente dos Riscos

isys | Revista Brasileira de Sistemas de Informação, Rio de Janeiro, vol. 9, No. 4, pp. 05-37, 2016 
revela a sua origem no italiano antigo, riscare, cujo significado é "ousar", portanto, sua conotação original implica não apenas em prejuízo (compreensão usual), mas também em ganho decorrente de uma decisão do fato de aproveitarmos as oportunidades que surgem [Baldam, 2014]. A visão do risco tanto como um evento positivo (oportunidade) quanto como um evento negativo (ameaça) será a adotada neste trabalho.

Uma vez que o risco pode ser potencialmente danoso ou benéfico ao alcance dos objetivos da organização, torna-se consenso que o mesmo deve ser gerenciado. Para a ISO 31000:2009 (Associação Brasileira de Normas Técnicas [ABNT, 2009]), o gerenciamento de riscos consiste em atividades coordenadas para dirigir e controlar uma organização no que se refere a riscos, tratando riscos como efeitos inesperados, sejam eles positivos ou negativos. Assim, o principal objetivo do gerenciamento de riscos é garantir que todas as oportunidades e ameaças para a organização sejam identificadas e controladas.

Como o gerenciamento de riscos é um tema amplamente discutido em diversas áreas, existem diversos modelos propostos na literatura para esta finalidade. Portanto, uma das fases deste estudo consistiu em analisar os principais modelos de gerenciamento de riscos existentes e identificar o mais adequado para ser integrado com BPM (conforme descritas as QP1 e QP2). A Tabela 1 apresenta os modelos analisados e o foco dado por cada um com relação aos tipos de riscos.

Tabela 1. Foco dado, de acordo com o tipo de risco, pelas abordagens de gerenciamento de riscos analisadas

\begin{tabular}{|l|c|}
\hline \multicolumn{1}{|c|}{ Modelos para Gerenciamento de Riscos } & Tipos de Riscos \\
\hline PMBOK® Guide, 2012 (PMI, 2012) & Riscos em Projetos \\
\hline ISO 31000:2009 (ABNT,2009) & Riscos em geral \\
\hline $\begin{array}{l}\text { Guia de Orientação para Gerenciamento de } \\
\text { Riscos Corporativos (IBGC, 2007) }\end{array}$ & Riscos Corporativos \\
\hline $\begin{array}{l}\text { COSO: Enterprise Risk Management - } \\
\text { Integrated Framework (COSO, 2004) }\end{array}$ & Riscos Corporativos \\
\hline
\end{tabular}

Conforme será detalhado na Seção 3.2, foram adotadas duas estratégias para a escolha do modelo, a pesquisa bibliográfica e a discussão com especialistas através de grupos focais. Para se chegar a um modelo de gerenciamento de riscos ideal foram considerados os seguintes critérios:

- Critério 1: Similaridade das etapas do modelo de gerenciamento de riscos com o ciclo de vida BPM;

- Critério 2: Foco dos modelos de gerenciamento de riscos com relação aos tipos de riscos, áreas ou organizações; $e$

○ Critério 3: Adoção do modelo pelo mercado.

A Tabela 2 apresenta as principais atividades de cada modelo de gerenciamento de riscos e a fase do ciclo de vida BPM com que cada atividade possui maior similaridade. 
Tabela 2. Abordagens de gerenciamento de riscos analisadas e suas etapas

\begin{tabular}{|c|c|c|c|c|}
\hline Fases BPM & PMBOK® 2012 & ISO 31000:2009 & IBGC, 2007 & COSO, 2004 \\
\hline Planejamento & $\begin{array}{c}\text { Planejar o } \\
\text { gerenciamento de } \\
\text { riscos }\end{array}$ & $\begin{array}{l}\text { Estabelecimento } \\
\text { do contexto }\end{array}$ & & $\begin{array}{l}\text { Fixação de } \\
\text { Objetivos }\end{array}$ \\
\hline $\begin{array}{l}\text { Modelagem } \\
\text { (As IS) }\end{array}$ & $\begin{array}{l}\text { Identificar os } \\
\text { riscos }\end{array}$ & $\begin{array}{l}\text { Identificação de } \\
\text { Riscos }\end{array}$ & $\begin{array}{l}\text { Identificação e } \\
\text { Classificação } \\
\text { dos Riscos }\end{array}$ & $\begin{array}{l}\text { Identificação } \\
\text { de Eventos }\end{array}$ \\
\hline $\begin{array}{l}\text { Análise do } \\
\text { Processo }\end{array}$ & $\begin{array}{c}\text { Realizar a análise } \\
\text { qualitativa dos } \\
\text { riscos } \\
\text { Realizar análise } \\
\text { quantitativa dos } \\
\text { riscos } \\
\end{array}$ & Análise de Riscos & $\begin{array}{c}\text { Avaliação dos } \\
\text { Riscos } \\
\text { Mensuração } \\
\text { dos Riscos }\end{array}$ & $\begin{array}{l}\text { Avaliação de } \\
\text { Riscos }\end{array}$ \\
\hline $\begin{array}{c}\text { Desenho (TO } \\
\text { BE) }\end{array}$ & $\begin{array}{l}\text { Planejar as } \\
\text { respostas aos } \\
\text { riscos }\end{array}$ & $\begin{array}{l}\text { Avaliação de } \\
\text { Riscos }\end{array}$ & $\begin{array}{l}\text { Tratamento } \\
\text { dos Riscos }\end{array}$ & $\begin{array}{l}\text { Resposta a } \\
\quad \text { Risco }\end{array}$ \\
\hline Implementação & & $\begin{array}{c}\text { Tratamento de } \\
\text { riscos }\end{array}$ & & $\begin{array}{l}\text { Atividades de } \\
\text { Controle }\end{array}$ \\
\hline \multirow[t]{3}{*}{$\begin{array}{c}\text { Monitoramento } \\
\text { e Controle }\end{array}$} & $\begin{array}{c}\text { Monitorar e } \\
\text { controlar os riscos }\end{array}$ & $\begin{array}{l}\text { Monitoramento e } \\
\text { Análise Crítica }\end{array}$ & $\begin{array}{l}\text { Monitoramento } \\
\text { dos Riscos }\end{array}$ & Monitoramento \\
\hline & & $\begin{array}{c}\text { Comunicação e } \\
\text { Consulta }\end{array}$ & $\begin{array}{l}\text { Informação e } \\
\text { Comunicação }\end{array}$ & $\begin{array}{l}\text { Informações e } \\
\text { Comunicações }\end{array}$ \\
\hline & & & & $\begin{array}{c}\text { Ambiente } \\
\text { Interno }\end{array}$ \\
\hline
\end{tabular}

É importante destacar que, apesar da ISO 31000:2009 ter atividades com nomes semelhantes às atividades de outros modelos, estas foram posicionadas em locais diferentes na Tabela 2 pois suas ações são as mesmas realizadas por atividades com outros nomes nos outros modelos. Por exemplo: "Avaliação de Riscos" da ISO representa a escolha da resposta ao risco assim como no COSO e no PMBOK, mas o IBGC trata esta atividade como "Tratamento dos Riscos". Já na ISO, o tratamento de riscos representa ações para controlar os riscos e a implementação destas ações.

Como resultado dessa análise, foi constatado que apesar de suas diferenças, todos os modelos têm em comum as atividades de identificar riscos, avaliar riscos, definir respostas a riscos e monitorar os riscos. Como o gerenciamento de riscos deve ser realizado de forma cíclica, pois novos riscos podem surgir a qualquer momento, as atividades que são comuns a todo modelo de gerenciamento de riscos seguem um formato muito parecido com as fases do ciclo de vida BPM, o qual se assemelha com o ciclo de Deming, o famoso PDCA.

Nas discussões do grupo focal com especialistas em riscos e BPM, foi informado que a SEC (Securities and Exchange Commission), responsável pela implantação da lei Sarbanes-Oxley (SOX), cita o COSO como a estrutura de gerenciamento de riscos mais recomendada ${ }^{1}$. Por isso, essa tem sido a abordagem mais adotada pelas organizações e foi também a abordagem adotada neste trabalho. A justificativa dessa escolha se deve ao enfoque de gestão corporativa do COSO. Essa visão é alinhada com a perspectiva do Gerenciamento de Processos de Negócio, conforme explicado na seção a seguir.

\footnotetext{
${ }^{1}$ https://www.sec.gov/rules/final/33-8238.htm

FERREIRA, F. S.; ALVES, C. F.; CAVALCANTI, R. C.

R-BPM: Uma Metodologia para Gerenciamento de Processos de Negócios Consciente dos Riscos

isys | Revista Brasileira de Sistemas de Informação, Rio de Janeiro, vol. 9, No. 4, pp. 05-37, 2016
} 


\subsection{Trabalhos Relacionados}

A primeira fase desta pesquisa consistiu na realização de uma pesquisa bibliográfica com o objetivo de identificar na literatura as abordagens existentes para gerenciar riscos de forma integrada com BPM e suas limitações. Suriadi et. al. (2014) realizou uma revisão sistemática da literatura sobre as principais pesquisas na área de Risk-Aware Business Process Management (R-BPM). Nessa revisão sistemática, os autores fizeram uma comparação entre as abordagens propostas até então, e uma análise das principais lacunas existentes na área. Além disso, eles propuseram uma agenda de pesquisa para as principais lacunas encontradas. Para estabelecer os critérios de análise dos trabalhos existentes, a pesquisa bibliográfica realizada neste artigo se baseou nos resultados do trabalho de Suriadi et. al. (2014). Os critérios utilizados foram:

- Critério 1: O trabalho analisado se baseia em alguma abordagem consagrada de gerenciamento de riscos?

- Critério 2: Quais atividades de gerenciamento de riscos são utilizadas pelos trabalhos analisados?

- Critério 3: São realizadas atividades de gerenciamento de riscos em quais fases do ciclo de vida BPM?

- Critério 4: A proposta analisada teve alguma aplicação prática ou apresenta instruções para tal?

A Tabela 3 apresenta os trabalhos analisados e a principal característica de cada um deles.

Tabela 3. Trabalhos relacionados analisados e características

\begin{tabular}{|c|l|l|}
\hline Cód. & \multicolumn{1}{|c|}{ Trabalho } & \multicolumn{1}{c|}{ Principal Característica } \\
\hline P01 & $\begin{array}{l}\text { Sienou et al. } \\
(2010)\end{array}$ & $\begin{array}{l}\text { Propõem um framework chamado Business Process Risk Management } \\
\text { Integrated Method (BPRIM) onde as atividades de modelagem do } \\
\text { processo são combinadas com atividades de gerenciamento de riscos. } \\
\text { Utiliza uma extensão da UML (diagrama de classes) para modelar riscos } \\
\text { em processos de negócios. }\end{array}$ \\
\hline P02 & Betz et al. (2011) & $\begin{array}{l}\text { Apresenta uma metodologia de modelagem de processos de negócios } \\
\text { com consciência dos riscos e uma ferramenta para auxiliá-la. Utiliza uma } \\
\text { variação das redes de Petri modelar os riscos o diagrama de classes da } \\
\text { UML também é utilizado para representar eventos de riscos. }\end{array}$ \\
\hline P03 & $\begin{array}{l}\text { Weiss e } \\
\text { Winkelmann, }\end{array}$ & $\begin{array}{l}\text { Propõem construções para representar informações relacionadas com } \\
\text { riscos nos modelos de processos de negócios. Foi desenvolvido no } \\
\text { domínio financeiro e por isso é baseado no Acordo de Basiléia II. Utiliza } \\
\text { o diagrama de Entidade e Relacionamento (ER) para especificar os } \\
\text { blocos de construções propostos. }\end{array}$ \\
\hline P04 & $\begin{array}{l}\text { Rotaru et al. } \\
\text { (2011) }\end{array}$ & $\begin{array}{l}\text { Esse trabalho tem como objetivo fornecer um conjunto de construções } \\
\text { necessárias para representar o risco em modelos de processos de } \\
\text { negócios. Também utiliza o diagrama de entidade e relacionamento para } \\
\text { especificar as construções. }\end{array}$ \\
\hline P05 & Cope et al. (2010) & $\begin{array}{l}\text { Propõem uma extensão de BPMN para representar informações } \\
\text { relacionadas com riscos. }\end{array}$ \\
\hline P06 & Islam et al. (2009) & $\begin{array}{l}\text { Propõem técnicas para identificar e estimar o impacto da ocorrência de } \\
\text { riscos para os processos de negócios utilizando modelos organizacionais. }\end{array}$ \\
\hline Pallow et al. & $\begin{array}{l}\text { Nesse trabalho é proposto um framework para identificar e analisar } \\
\text { riscos em processos de negócios. É dado foco para os riscos operacionais } \\
\text { e são propostas técnicas para estimar o impacto gerado pela ocorrência } \\
\text { de eventos de risco nos processos de negócios. }\end{array}$ \\
\hline
\end{tabular}

FERREIRA, F. S.; ALVES, C. F.; CAVALCANTI, R. C.

R-BPM: Uma Metodologia para Gerenciamento de Processos de Negócios Consciente dos Riscos

isys | Revista Brasileira de Sistemas de Informação, Rio de Janeiro, vol. 9, No. 4, pp. 05-37, 2016 


\begin{tabular}{|c|l|l|}
\hline Cód. & \multicolumn{1}{|c|}{ Trabalho } & \multicolumn{1}{c|}{ Principal Característica } \\
\hline P08 & Fenz et al. (2009) & $\begin{array}{l}\text { Nesse trabalho são propostas técnicas para análise de riscos em } \\
\text { processos levando em consideração tanto a probabilidade quanto o } \\
\text { impacto dos mesmos. Para estimar a probabilidade e o impacto dos } \\
\text { riscos são utilizadas Redes Bayesianas e Redes de Petri respectivamente. }\end{array}$ \\
\hline P09 & $\begin{array}{l}\text { Conforti et al. } \\
(2011)\end{array}$ & $\begin{array}{l}\text { Nesse trabalho é proposta uma abordagem para identificar riscos em } \\
\text { processos de negócios executáveis em tempo de execução. A arquitetura } \\
\text { proposta é implementada no BPMS YAWL. }\end{array}$ \\
\hline P10 & $\begin{array}{l}\text { Wickbold et al. } \\
(2011)\end{array}$ & $\begin{array}{l}\text { Nesse trabalho é proposto um framework para capturar informações } \\
\text { relacionadas com riscos nos logs da execução dos processos. Técnicas } \\
\text { para identificar e avaliar riscos sobre as informações capturadas também } \\
\text { são propostas. }\end{array}$ \\
\hline P11 & Jans et al. (2011) & $\begin{array}{l}\text { Propõem analisar os registros históricos dos processos de negócios com } \\
\text { o objetivo de identificar ou estimar a probabilidade de ocorrência de } \\
\text { riscos relacionados com fraudes financeiras. Utiliza a ferramenta ProM }{ }^{2} .\end{array}$ \\
\hline P12 & $\begin{array}{l}\text { Haggag, Khedr e } \\
\text { Montasser (2015) }\end{array}$ & $\begin{array}{l}\text { Propõem um modelo para identificar riscos em todas as fases do ciclo de } \\
\text { vida BPM. }\end{array}$ \\
\hline
\end{tabular}

A Tabela 4 apresenta o resultado da análise dos trabalhos listados na Tabela 3 com relação aos critérios 1 e 2 . Com relação ao critério 1, "O trabalho analisado se baseia em alguma abordagem consagrada de gerenciamento de riscos?", a coluna "Modelos de Riscos" informa se o trabalho adota algum modelo ou abordagem de gerenciamento de risco consagrados na literatura ou no mercado. Foram destacados com o fundo preto os trabalhos que realmente utilizam algum modelo ou abordagem de riscos, os demais, apenas citam ou sofrem algum tipo de influência desses. Através da Tabela 4 é possível constatar que o número de trabalhos que adota alguma abordagem consagrada de gerenciamento de riscos é muito baixo.

Tabela 4. Análise das abordagens com relação às atividades de gerenciamento de riscos e aos frameworks de gerenciamento de riscos existentes.

\begin{tabular}{|c|c|c|c|c|c|c|c|}
\hline \multirow[b]{2}{*}{ Cód. } & \multicolumn{2}{|c|}{ Identificação de Riscos } & \multicolumn{2}{|c|}{ Análise de Riscos } & \multirow{2}{*}{$\begin{array}{c}\text { Respostas } \\
\text { a Riscos }\end{array}$} & \multirow{2}{*}{$\begin{array}{c}\text { Atividades } \\
\text { de } \\
\text { Controle }\end{array}$} & \multirow{2}{*}{$\begin{array}{l}\text { Modelos } \\
\text { de Riscos }\end{array}$} \\
\hline & $\begin{array}{c}\text { Identificação } \\
\text { de Riscos }\end{array}$ & $\begin{array}{l}\text { Anotação } \\
\text { de Riscos }\end{array}$ & Probabilidade & Impacto & & & \\
\hline P01 & $\mathrm{X}$ & $\mathrm{X}$ & & & $\mathrm{X}$ & $\mathrm{X}$ & $\mathrm{COSO}$ \\
\hline P02 & $\mathrm{X}$ & $\mathrm{X}$ & & & & $\mathrm{X}$ & \\
\hline P03 & & $\mathrm{X}$ & & & & & Basiléia II \\
\hline P04 & & X & & & & X & \\
\hline P05 & X & $\mathrm{X}$ & & & & & COSO \\
\hline P06 & $\mathrm{X}$ & & & $\mathrm{X}$ & & & \\
\hline P07 & $\mathrm{X}$ & & & $X$ & & & coso \\
\hline P08 & & & $\mathrm{X}$ & $\mathrm{X}$ & $\mathrm{X}$ & & $\begin{array}{c}\text { NIST 800- } \\
\quad 30\end{array}$ \\
\hline P09 & & $\mathrm{X}$ & $\mathrm{X}$ & & & & \\
\hline P10 & $\mathrm{X}$ & $\mathrm{X}$ & $\mathrm{X}$ & $\mathrm{X}$ & $\mathrm{X}$ & & M_O_R \\
\hline P11 & $\mathrm{X}$ & & $\mathrm{X}$ & & & & \\
\hline P12 & $X$ & & & & & & \\
\hline
\end{tabular}

${ }^{2}$ http://www.promtools.org/prom6/

EERREIRA, F. S.; ALVES, C. F.; CAVALCANTI, R. C.

R-BPM: Uma Metodologia para Gerenciamento de Processos de Negócios Consciente dos Riscos

isys | Revista Brasileira de Sistemas de Informação, Rio de Janeiro, vol. 9, No. 4, pp. 05-37, 2016 
Já com relação ao critério 2 - "Quais atividades de gerenciamento de riscos são utilizadas pelos trabalhos analisados? ", foram consideradas para a análise as atividades que são comuns a praticamente todos os modelos de gerenciamento de riscos. Como alguns trabalhos propõem anotações para representar os riscos identificados nos modelos de processos de negócios e outros não, a atividade "Identificação de Riscos" foi dividida em duas, Identificação de Riscos e Anotação de Riscos. O mesmo foi feito com a atividade de "Análise de Riscos", já que alguns trabalhos levam em consideração apenas a análise da probabilidade ou do impacto da ocorrência do risco.

Com relação ao critério 3, "São realizadas atividades de gerenciamento de riscos em quais fases do ciclo de vida BPM?", a Tabela 5 faz um mapeamento dos trabalhos analisados mostrando em quais fases do ciclo de vida BPM é aplicada alguma atividade relacionada ao gerenciamento de riscos por esses trabalhos.

\section{Tabela 5. Fases do ciclo de vida BPM que são realizadas atividades de gerenciamento de riscos por trabalho}

\begin{tabular}{|c|c|c|c|c|c|c|}
\hline Cód. & Planejamento & Modelagem & Análise & Desenho & Implementação & Monitoramento \\
\hline P01 & & $\mathrm{X}$ & & & & \\
\hline P02 & & $\mathrm{X}$ & $\mathrm{X}$ & $\mathrm{X}$ & & \\
\hline P03 & & $\mathrm{X}$ & & & & \\
\hline P04 & & $\mathrm{X}$ & $\mathrm{X}$ & $\mathrm{X}$ & & \\
\hline P05 & & $\mathrm{X}$ & $\mathrm{X}$ & $\mathrm{X}$ & & \\
\hline P06 & & $\mathrm{X}$ & $\mathrm{X}$ & & \\
\hline P07 & & $\mathrm{X}$ & & & \\
\hline P08 & & $\mathrm{X}$ & & $\mathrm{X}$ & $\mathrm{X}$ & \\
\hline P09 & & & & & & $\mathrm{X}$ \\
\hline P10 & & & & & & $\mathrm{X}$ \\
\hline P11 & & $\mathrm{X}$ & $\mathrm{X}$ & $\mathrm{X}$ & $\mathrm{X}$ & $\mathrm{X}$ \\
\hline P12 & & &
\end{tabular}

De acordo com a Tabela 5, é possível constatar que apenas o trabalho de Haggag, Khedr E Montasser (2015) (P12) possui alguma atividade de gerenciamento de riscos contemplando quase todas as fases do ciclo de vida BPM. No entanto, ao analisar a Tabela 4 é possível constatar que a única atividade de gerenciamento de riscos realizada por essa proposta é a de identificação de riscos.

Finalmente, o critério 4 (“A proposta analisada teve alguma aplicação prática ou apresenta instruções para tal?") visa avaliar os trabalhos com relação à sua aplicabilidade prática, se eles foram aplicados na prática e/ou se propõem metodologias ou orientações para a sua aplicação. A Tabela 6 mostra quais trabalhos analisados foram aplicados na prática e quais apresentam metodologias ou orientações para aplicação.

Tabela 6. Aplicabilidade prática dos trabalhos analisados

\begin{tabular}{|l|c|c|c|c|c|c|c|c|c|c|c|c|}
\hline & P01 & P02 & P03 & P04 & P05 & P06 & P07 & P08 & P09 & P10 & P11 & P12 \\
\hline Aplicação Prática & & & $\mathrm{X}$ & & & $\mathrm{X}$ & $\mathrm{X}$ & $\mathrm{X}$ & $\mathrm{X}$ & & & $\mathrm{X}$ \\
\hline $\begin{array}{l}\text { Metodologia para } \\
\text { aplicação }\end{array}$ & $\mathrm{X}$ & $\mathrm{X}$ & $\mathrm{X}$ & & $\mathrm{X}$ & & & & & $\mathrm{X}$ & & $\mathrm{X}$ \\
\hline
\end{tabular}


Através das análises foi possível constatar que os trabalhos, em sua maioria, são aplicados nas fases iniciais do ciclo de vida BPM (antes da execução do processo) e estão relacionados com a definição de artefatos para comunicar os riscos através de modelos de processos de negócios. Existem poucas abordagens que propõem atividades de gerenciamento de riscos durante ou depois da fase de execução dos processos de negócio.

Através da análise dos critérios foi possível constatar também que o número de trabalhos que utilizam abordagens de gerenciamento riscos existentes no domínio de BPM é muito baixo, e aqueles que utilizam não tratam os riscos em todas as fases do ciclo de vida BPM. Além disso, muitos trabalhos sobre o tema não tiveram aplicabilidade prática. Assim, a principal lacuna encontrada foi a não utilização de abordagens de gerenciamento de riscos existentes e consagradas no mercado para o contexto de BPM. Para Suriadi et. al. (2014), com as técnicas comprovadamente eficazes e maduras existentes no domínio de gerenciamento de riscos, não precisamos perder tempo propondo novas técnicas de análise de riscos, em vez disso, podemos nos concentrar no desenvolvimento de métodos que permitam a aplicação e adequação dessas técnicas de forma integrada em várias fases do ciclo de vida BPM.

Este artigo apresenta uma contribuição que visa preencher a lacuna de integração entre modelos de gerenciamento de riscos e BPM. A proposta visa integrar a estrutura de gerenciamento de riscos do COSO com o ciclo de vida BPM através da metodologia R-BPM.

\section{Método de Pesquisa}

Esta seção descreve o método de pesquisa adotado. A Figura 2 destaca cada fase da pesquisa em termos de: objetivo específico, questões de pesquisa e estratégias de pesquisa associadas ao objetivo. A primeira fase consistiu em responder a QP1 (Quais são as abordagens existentes para gerenciar riscos de forma integrada com BPM $e$ quais são as suas limitações?). A estratégia de pesquisa adotada foi a pesquisa bibliográfica que permitiu identificar, avaliar e interpretar as propostas existentes para gerenciar riscos em processos de negócios de forma integrada com BPM. Os resultados dessa etapa foram apresentados na Seção 2.4. A segunda fase da pesquisa investigou a QP2 (Qual é o modelo de gerenciamento de riscos mais adequado para ser integrado com BPM?). As estratégias de pesquisa utilizadas foram a pesquisa bibliográfica e grupos focais com especialistas das áreas de riscos e BPM. A pesquisa bibliográfica permitiu analisar os modelos de gerenciamento de riscos consagrados na literatura e identificar os que possuem maior relação com um ciclo de vida BPM genérico. Já as discussões com especialistas foram importantes para poder confrontar os modelos identificados na pesquisa bibliográfica com os modelos que são realmente utilizados no mercado, além de permitir discutir também qual modelo permite uma integração mais simples com o ciclo de vida BPM. Os resultados desta fase foram apresentados na Seção 2.3 .

A terceira fase da pesquisa é o núcleo central desta pesquisa e buscou responder a QP3 (Como gerenciar riscos em processos de negócios de forma integrada com o ciclo de vida BPM?). A estratégia de pesquisa adotada foi a de Design Science Research que é detalhada na Seção 3.1. A metodologia proposta como resultado dessa fase foi

FERREIRA, F. S.; ALVES, C. F.; CAVALCANTI, R. C.

R-BPM: Uma Metodologia para Gerenciamento de Processos de Negócios Consciente dos Riscos

isys | Revista Brasileira de Sistemas de Informação, Rio de Janeiro, vol. 9, No. 4, pp. 05-37, 2016 
chamada de R-BPM. Ela é composta por um conjunto de fases e de uma ferramenta de apoio que são apresentados na Seção 4.

Fase 1: Analisar as abordagens propostas na literatura de gerenciamento de riscos em processos de negócios.

(QP1) Quais são as abordagens existentes para gerenciar riscos de forma integrada com $B P M e$ quais são as suas limitações?

Pequisa Biblográfica

Fase 2: Analisar os modelos de gerenciamento de riscos existentes e identificar o mais adequado para ser integrado com BPM.

(QP2) Qual é o modelo de gerenciamento de riscos mais adequado para ser integrado com BPM?

Pequisa Biblográfica e Grupo Focal

Fase 3: Construir uma metodologia que permita realizar o gerenciamento de riscos em processos de negócios de forma integrada com o ciclo de vida BPM e uma ferramenta de software para apoiá-la.

(QP3) Como gerenciar riscos em processos de negócios de forma integrada com o ciclo de vida $B P M$ ?

Design Science Research

Fase 4: Avaliar a metodologia proposta e a sua ferramenta de apoio em uma organização experiente em BPM.

(QP4): Quais são os principais beneficios em gerenciar riscos de processos de negócios de forma integrada com BPM?
Estudo de caso (Grupos Focais com Especialistas e Questionário) (Inseridos na Design Science Research)

Figura 2. Fases da Pesquisa

A quarta fase da pesquisa envolveu um estudo de caso com o objetivo de avaliar a metodologia R-BPM e a sua ferramenta de apoio em uma organização experiente em BPM e buscou responder a QP4 (Quais são os principais benefícios em gerenciar riscos de processos de negócios de forma integrada com BPM?). O estudo de caso envolveu grupos focais e um questionário de avaliação com especialistas da organização. Essas estratégias estiveram inseridas na estratégia de Design Science Research escolhida para a construção da metodologia, a qual envolve um processo iterativo de construção e avaliação.

\subsection{Estratégia de Concepção da Metodologia R-BPM: Design-Science Research}

A Pesquisa de Ciência de Projeto (do original em inglês Design Science Research $D S R$ ) é uma metateoria que investiga a geração de conhecimento através do processo de FERREIRA, F. S.; ALVES, C. F.; CAVALCANTI, R. C.

R-BPM: Uma Metodologia para Gerenciamento de Processos de Negócios Consciente dos Riscos

isys | Revista Brasileira de Sistemas de Informação, Rio de Janeiro, vol. 9, No. 4, pp. 05-37, 2016 
concepção de artefatos. Assim, no paradigma DSR, o conhecimento, a compreensão de um domínio do problema e sua solução são alcançados graças à construção e aplicação de um artefato projetado [BAX, 2013].

$\mathrm{Na}$ área de tecnologia da informação, os artefatos podem ser dos tipos: construtos (entidades e relações), modelos (abstrações e representações), métodos (algoritmos e práticas) e instanciações (implementação de sistemas e protótipos) [Hevner et al. 2004]. Então, o objetivo principal deste artigo pode ser visto como um problema de DSR, já que o resultado pretendido - uma metodologia para gerenciar riscos em processos de negócios de forma integrada com o ciclo de vida BPM - é constituído de artefatos de TI como o modelo de fases (abstrações e representações) e a ferramenta de software de apoio (implementação de sistemas e protótipos).

É importante destacar a diferença entre DSR e o desenho de soluções de rotina ou construção de sistemas. De acordo com Hevner et al. (2004), a diferença está na natureza dos problemas e soluções. Para os autores, o desenho de soluções de rotinas é a aplicação do conhecimento existente para resolver problemas organizacionais, tais como a construção de um sistema de informação administrativo ou acadêmico, utilizando as melhores práticas existentes na base de conhecimento para construir os artefatos necessários (construções, modelos, métodos e instanciações). Já a DSR aborda a pesquisa de solução, de forma única ou inovadora, para problemas importantes ainda não resolvidos, ou mesmo para problemas que já foram resolvidos, mas não da forma mais eficaz ou eficiente. Assim, o principal diferenciador entre o desenho de soluções de rotina e a Design Science Research é a identificação clara de uma contribuição relevante para a base de conhecimento de fundamentações e metodologias sobre o problema abordado.

Assim sendo, a metodologia R-BPM pretendida como resultado deste trabalho enquadra-se como desenho de solução de um problema de conhecimento, que está caracterizado na principal questão de pesquisa deste artigo: (QP3) Como gerenciar riscos em processos de negócios de forma integrada com o ciclo de vida BPM?

De acordo com Hevner et al. (2004), a Design Science Research envolve basicamente dois processos: construir e avaliar, que se alternam de forma iterativa e incremental. O processo de construção, envolve uma sequência de atividades que produz um produto inovador (isto é, o artefato de criação) que será avaliado pelo processo de avaliação. O processo de avaliação do artefato fornece informações de retorno e uma melhor compreensão do fenômeno, a fim de melhorar tanto a qualidade do artefato gerado quanto do processo de construção. Esse ciclo de construir e avaliar é realizado iterativamente várias vezes antes de o artefato final ser gerado [MARKUS et al. 2002]. Para a obtenção do modelo de fases e da ferramenta de apoio da metodologia R-BPM foi utilizado o ciclo construir-avaliar conforme ilustrado na Figura 3. O lado esquerdo da figura representa de forma sintética os resultados da construção incremental da metodologia R-BPM. Conforme descrito na Figura 3, cada ciclo construir-avaliar produz versões incrementais da metodologia (Incremento 1, Incremento 2, ..., Incremento $\mathrm{n}$ ). Ao todo foram realizadas 3 avaliações dos incrementos através de grupos focais.

FERREIRA, F. S.; ALVES, C. F.; CAVALCANTI, R. C.

R-BPM: Uma Metodologia para Gerenciamento de Processos de Negócios Consciente dos Riscos

isys | Revista Brasileira de Sistemas de Informação, Rio de Janeiro, vol. 9, No. 4, pp. 05-37, 2016 


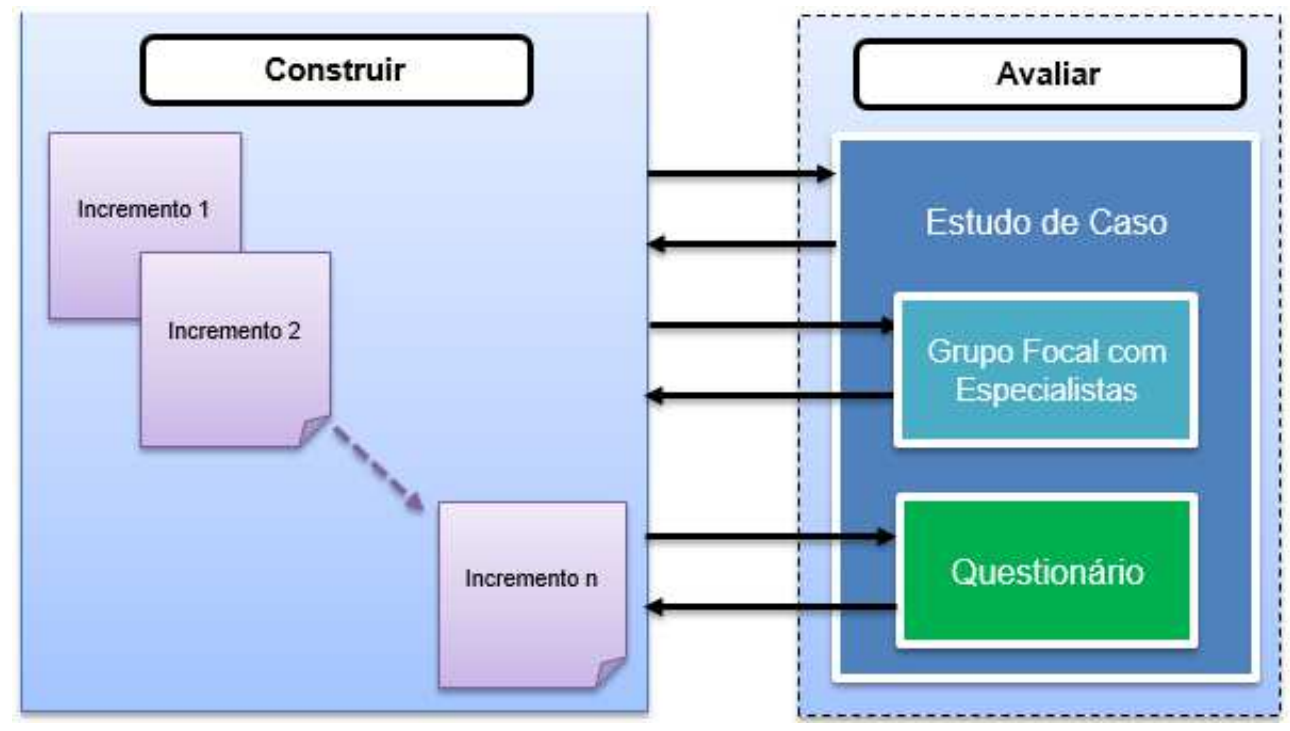

Figura 3. Ciclo Construir-Avaliar da Metodologia adotada neste trabalho

\subsection{Estratégia de Avaliação da Metodologia: Estudo de Caso}

O mecanismo adotado nesta pesquisa para avaliação da metodologia R-BPM, como parte da abordagem de pesquisa Design Science, foi o estudo de caso. Segundo PriesHeje, Baskerville e Venable (2008), o estudo de caso é uma das estratégias recomendadas para avaliação de trabalhos que utilizam a abordagem de DSR. De acordo com Yin (2001), um estudo de caso investiga um fenômeno contemporâneo dentro do contexto da vida real, especialmente quando os limites entre o fenômeno e o contexto não estão claramente definidos. Sendo assim, foi realizado um estudo de caso em uma organização experiente em BPM para avaliação da metodologia. A seção 5 descreve o estudo de caso realizado para avaliação da metodologia R-BPM.

\section{Metodologia R-BPM}

A metodologia R-BPM, representada na Figura 4, possui o mesmo funcionamento do ciclo de vida BPM, assumindo a forma cíclica com as atividades organizadas em fases e se repetindo a cada ciclo. Visando identificar a origem das fases da metodologia R-BPM na Figura 4, foi dado um destaque com a cor cinza claro para as fases do ciclo de vida BPM proposto por Oliveira (2014) e com a cor cinza escuro para os componentes da estrutura de gerenciamento de riscos do COSO. No topo da metodologia está representado o Ambiente Interno, que dita como o negócio é gerido e fornece a base para o gerenciamento de riscos. $\mathrm{O}$ ambiente interno engloba toda a organização e fornece a base pela qual os riscos são identificados e abordados pelo seu pessoal [COSO, 2004]. O Ambiente Interno influencia a execução da metodologia e é influenciado pelos resultados desta.

Durante a execução de cada fase, podem ser identificadas informações relevantes que deverão ser comunicadas aos responsáveis para que sejam tomadas as devidas providências. A fase de Informações e Comunicações está representada no centro por interagir com as demais fases o tempo todo. Ao final de cada iteração no ciclo, na fase de Monitoramento e Controle, é realizada uma análise da iteração antes de se iniciar uma nova. Esse processo é chamado de melhoria contínua.

FERREIRA, F. S.; ALVES, C. F.; CAVALCANTI, R. C.

R-BPM: Uma Metodologia para Gerenciamento de Processos de Negócios Consciente dos Riscos

isys | Revista Brasileira de Sistemas de Informação, Rio de Janeiro, vol. 9, No. 4, pp. 05-37, 2016 


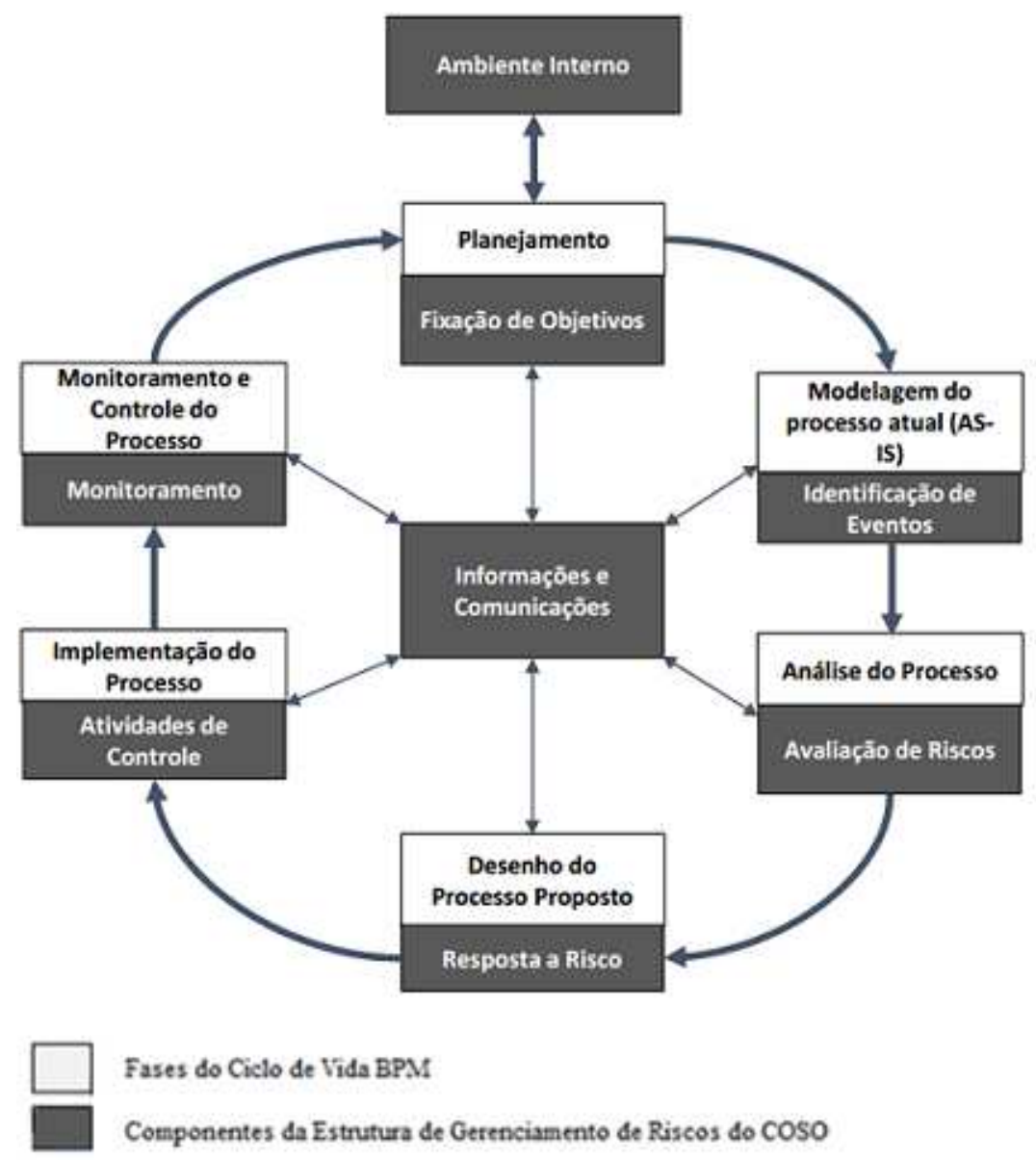

Figura 4. Visão Geral da Metodologia R-BPM

A fase de planejamento do ciclo de vida BPM e o componente fixação de objetivos do COSO (2004) foram agrupados pois o projeto BPM necessita estar alinhado com a estratégia da organização. Assim, nessa fase é necessário fixar os objetivos no âmbito estratégico e alinhar o projeto BPM com a estratégia da organização. A partir dos objetivos é possível estabelecer o apetite a riscos da organização.

A fase de modelagem do processo atual (AS-IS) do ciclo de vida BPM foi agrupada com o componente de identificação de eventos do COSO (2004). $\mathrm{O}$ agrupamento foi feito pois nessa fase é realizado o levantamento das informações necessárias para o entendimento do processo e, em seguida, modelado o processo atual. Assim, durante o entendimento e modelagem do processo atual, é possível identificar eventos e classificá-los entre riscos e oportunidades.

A fase de análise do processo foi agrupada ao componente de avaliação de riscos do COSO (2004), pois nessa fase são identificados problemas no processo atual. Assim, aproveitamos para analisar os riscos considerando-se a sua probabilidade de ocorrência e o impacto para que eles possam ser administrados. Além disso, nessa fase são estabelecidos indicadores que permitam mensurar e quantificar o estado do processo atual para que seja possível saber se o processo terá melhoras no futuro.

A fase de desenho do processo proposto (TO BE) e o componente resposta a risco do COSO foram agrupados pois essa fase busca realizar o tratamento adequado para os problemas encontrados na etapa anterior, estejam eles relacionados a processos ou a riscos. No caso de problemas na execução dos processos, são propostas mudanças FERREIRA, F. S.; ALVES, C. F.; CAVALCANTI, R. C.

R-BPM: Uma Metodologia para Gerenciamento de Processos de Negócios Consciente dos Riscos

isys | Revista Brasileira de Sistemas de Informação, Rio de Janeiro, vol. 9, No. 4, pp. 05-37, 2016 
para solucioná-los, no caso de riscos na execução dos processos, são definidas as respostas aos riscos (evitar, aceitar, reduzir ou compartilhar) de acordo com a tolerância e apetite a risco da organização.

A fase de implementação foi agrupada com o componente atividades de controle do COSO pois nessa fase ocorre a implementação de políticas e procedimentos novos ou revisados, incluindo procedimentos que asseguram que as respostas aos riscos sejam executadas. Ainda, nessa etapa são executadas as atividades necessárias para operacionalizar o processo proposto (TO BE).

A fase de monitoramento e controle do processo foi agrupada com o componente monitoramento do COSO. Essa fase tem como objetivo identificar o desempenho do processo e tornar possível a sua melhoria e consequentemente seu desempenho. Além disso, o processo de gestão de riscos é constantemente monitorado e as modificações necessárias são realizadas.

A seguir, será detalhada cada fase da metodologia. Visando melhorar o entendimento das funcionalidades da ferramenta e da forma como ela apoia a metodologia, foi adotado como exemplo o processo de negócio de prestação de contas de uma organização pública. Maiores detalhes sobre o funcionamento da ferramenta podem ser encontrados no seu manual disponível no endereço eletrônico https://sites.google.com/a/cin.ufpe.br/modelo-r-bpm/a-ferramenta-r-bpm.

\subsection{Ambiente Interno}

O ambiente interno representa o ambiente em que a organização está inserida e não uma fase propriamente dita com um conjunto de atividades e saídas predefinidas. Ele fornece a base pela qual os riscos são identificados e abordados pelos gestores através de vários elementos, incluindo a estrutura organizacional, recursos humanos, filosofia de gerenciamento de riscos, o apetite a risco, conselho de administração, a integridade e os valores éticos, além do ambiente em que esses estão [COSO, 2004]. O impacto de um ambiente interno ineficaz pode ir muito longe e talvez provocar prejuízos financeiros, desgastes da imagem pública ou, até mesmo, o fracasso. Para que uma organização possa desfrutar de um gerenciamento de riscos eficaz, a atitude e o interesse da alta administração devem ser claros e definitivos, além de permear toda a organização.

\subsection{Fase Planejamento e Fixação de Objetivos}

A fase de planejamento e fixação de objetivos da metodologia R-BPM é a fase inicial do ciclo, antes de iniciar qualquer atividade dentro do ciclo, é necessário que os objetivos estratégicos estejam fixados e alinhados com a missão da organização. Com os objetivos estratégicos fixados, é possível realizar o alinhamento dos processos com a estratégia da organização. Nessa etapa é possível obter uma visão geral do processo, de modo a conseguir estimar o esforço necessário para a realização do projeto de BPM. São estabelecidos objetivos e as metas do processo, além de delimitado o seu escopo.

Tendo sido definida a estratégia da organização pode-se definir também o apetite a riscos da mesma. $\mathrm{O}$ apetite a risco é a quantidade de riscos, no sentido mais amplo, que uma organização está disposta a aceitar em sua busca para agregar valor [COSO, 2004:20]. Esse apetite pode ser considerado de forma qualitativa, categorizando-o como FERREIRA, F. S.; ALVES, C. F.; CAVALCANTI, R. C.

R-BPM: Uma Metodologia para Gerenciamento de Processos de Negócios Consciente dos Riscos

isys | Revista Brasileira de Sistemas de Informação, Rio de Janeiro, vol. 9, No. 4, pp. 05-37, 2016 
elevado, moderado ou baixo, ou de forma quantitativa que reflete e equilibra as metas de crescimento, retorno e risco [COSO, 2004].

Ainda, a partir da estratégia da organização é possível definir a tolerância a riscos da mesma, que é o nível de variação aceitável quanto à realização de um determinado objetivo. Por exemplo, um setor da organização fixa a sua meta de entregas pontuais em $90 \%$, com uma variação aceitável na faixa de $80 \%$ a $100 \%$ das vezes [COSO, 2004]. Um processo dentro dos parâmetros de tolerâncias a riscos possibilita à administração maior garantia de que ela permanecerá dentro de seu apetite a risco, o qual, por sua vez, possibilita um grau mais elevado de confiança para que seus objetivos possam ser atingidos. Para apoiar a realização dessa fase, a ferramenta de apoio da metodologia R-BPM permite: definir os objetivos estratégicos da organização; cadastrar processos de negócios; definir os objetivos de cada processo de negócio e alinhá-los com os objetivos estratégicos da organização; definir o apetite a riscos da organização; e definir categorias para agrupar os riscos;

Por exemplo, no caso do processo de prestação de contas, depois de definidos os objetivos estratégicos da organização, é possível cadastrar o processo, definir seus objetivos e alinhar esses objetivos aos objetivos estratégicos da organização, conforme ilustrado nas figuras 5 e 6 .

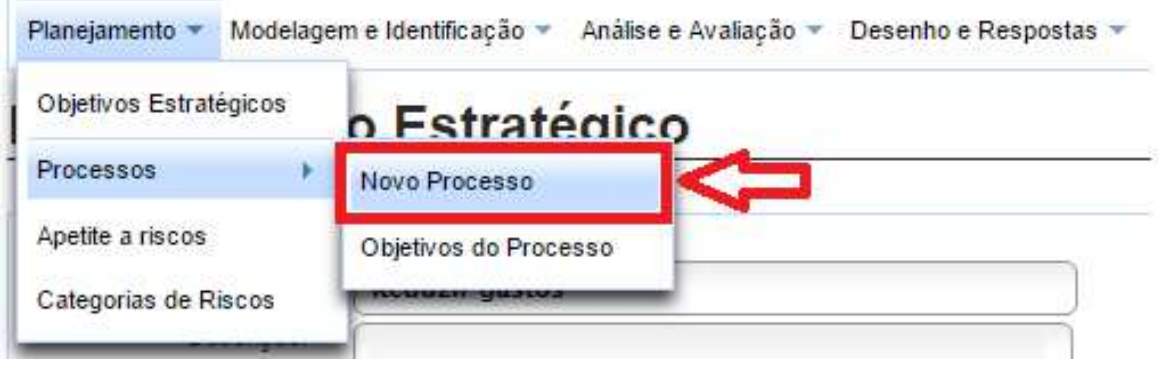

Figura 5. Selecionando a opção Objetivos do Processo na ferramenta R-BPM

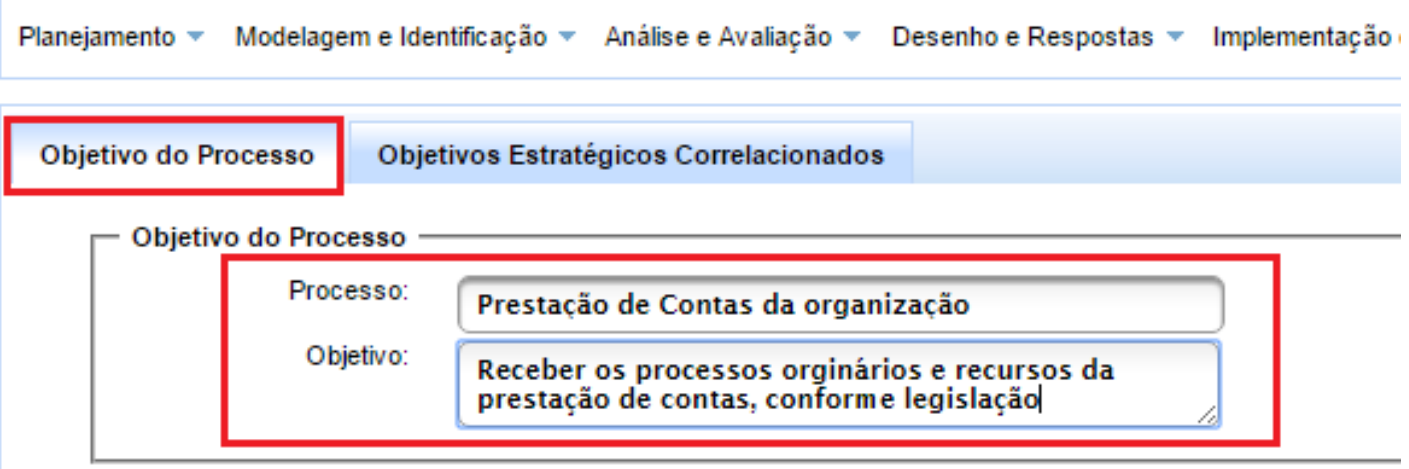

Figura 6. Definindo o objetivo do processo (aba objetivo do processo)

A ferramenta fornece uma opção para fazer uma avaliação qualitativa dos riscos, através da definição do apetite a riscos da organização, conforme ilustra a Figura 7. 


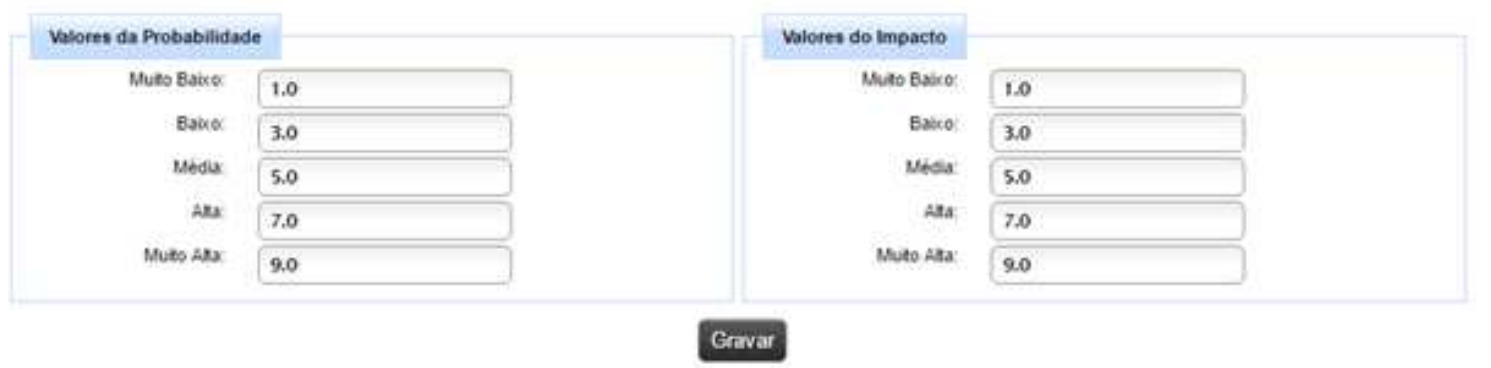

\begin{tabular}{|c|c|c|c|c|c|c|}
\hline \multicolumn{7}{|c|}{ Impacto } \\
\hline \multirow{6}{*}{ 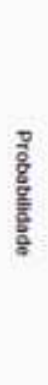 } & . & Muito Baixo & Baixo & Médio & Alto & Muito Alto \\
\hline & Muito Baixa & Muiso Baika & Muito Baica & Baba & Baksa & Baixa \\
\hline & Baba & Muito Baixa & Babra: & Media & Media & Mèdia : \\
\hline & Media & Baika & Modia & Méla & Ata & Arta \\
\hline & Alta & Batca & Media & Ata & Alte & Muldo Nata \\
\hline & Muito Alla & Bakra & Media & Ata & Muitp Aita & Muto Aita \\
\hline
\end{tabular}

Figura 7. Interface de definição do apetite a riscos com valores preenchidos

\subsection{Fase Modelagem do Processo Atual e Identificação de Eventos}

A fase de modelagem do processo atual e identificação de eventos visa entender como o processo funciona atualmente e identificar eventos que possam representar riscos e oportunidades para o processo. Para o entendimento do processo, são aplicadas algumas técnicas como: entrevistas, observações, questionários, análise de documentos e análise de sistemas. Nessa etapa não devemos buscar o processo correto, aqui é modelado o que é feito, esteja correto ou não [Oliveira, 2014].

As técnicas utilizadas para entendimento do processo também podem ser utilizadas para identificação de riscos. Portanto, durante as atividades realizadas para entendimento do processo aproveitamos para identificar eventos em potencial que, se ocorrerem, afetarão os objetivos do processo. Durante sua identificação, um evento deve ser diferenciado entre ameaça (risco negativo) e oportunidade (risco positivo). Eventos de impacto negativo representam riscos que exigem avaliação e resposta da administração. Já os eventos de impacto positivo representam oportunidades que são canalizadas de volta aos processos de fixação dos objetivos [COSO, 2004].

Como saída dessa fase, teremos o modelo do processo atual (AS IS) que pode ser feito utilizando a notação BPMN (do inglês Business Process Model and Notation) e a lista de eventos identificados, diferenciados em oportunidades (riscos positivos) e ameaças (riscos negativos) e classificados em categorias.

Para apoiar a realização dessa etapa, a ferramenta de apoio da metodologia RBPM permite cadastrar os eventos identificados informando o tipo do evento (positivo ou negativo), sua categoria, o processo ao qual o evento de risco está associado, além da 
descrição e consequência do evento. A Figura 8 ilustra o registro de um evento de risco para o processo de prestação de contas utilizado como exemplo neste artigo.

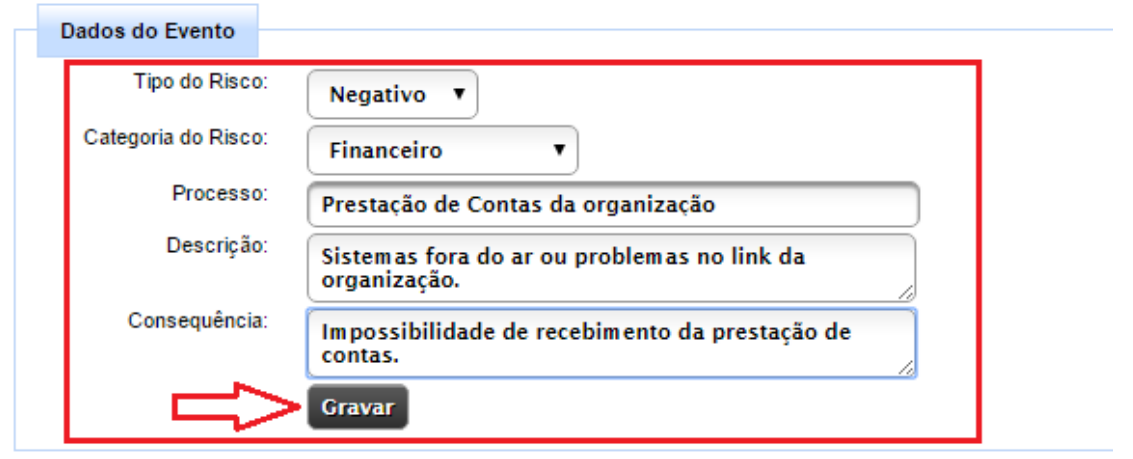

Figura 8. Cadastrando um novo evento de risco na ferramenta R-BPM

\subsection{Fase Análise do Processo e Avaliação dos Riscos}

A etapa de Análise do Processo e Avaliação de Riscos tem como objetivos identificar problemas no processo atual e avaliar os riscos do processo com relação à sua probabilidade de ocorrência e impacto para que eles possam ser administrados. Para identificação de problemas no processo atual são utilizadas técnicas de análise que devem ser selecionadas de acordo com o objetivo que se pretende alcançar. Algumas técnicas adotadas são a análise de causa-raiz ou espinha de peixe (Diagrama de Ishikawa), o brainstorming, o grupo focal, dentre outras [OLIVEIRA, 2014]. Nessa fase é possível que sejam identificados eventos de riscos que não foram identificados na fase anterior, assim, antes de analisar os novos eventos é necessário adicioná-los à ferramenta caracterizando-os como ameaças ou oportunidades e informando suas categorias.

A avaliação de riscos permite que a organização considere até que ponto eventos em potencial podem impactar a realização dos objetivos. A administração avalia os eventos com base em duas perspectivas: probabilidade e impacto. A probabilidade representa a possibilidade de que um determinado evento ocorra, enquanto o impacto representa o seu efeito [COSO, 2004]. Geralmente, as estimativas de probabilidade e impacto são feitas utilizando dados de eventos passados observáveis.

A metodologia de avaliação de riscos de uma organização pode utilizar técnicas qualitativas, quantitativas ou uma combinação de ambas. Geralmente, a administração emprega técnicas qualitativas quando os riscos não podem ser quantificados, ou se não há dados confiáveis em quantidade suficiente para a realização das avaliações quantitativas, ou, ainda, se a relação custo-benefício para obtenção e análise de dados não for viável [COSO, 2004]. Para apoiar a realização dessa etapa, a ferramenta de apoio da metodologia R-BPM permite avaliar os eventos de riscos identificados de acordo com sua probabilidade de ocorrência e impacto. A partir da probabilidade de ocorrência e impacto do risco é calculada a severidade do mesmo de acordo com o apetite a riscos da organização definido na fase de planejamento e fixação de objetivos conforme detalhado na Seção 4.2. A Figura 9 ilustra a avaliação de um evento de risco para o processo de prestação de contas utilizado como exemplo neste artigo. Já a Figura 10 mostra o mapa de gerenciamento de riscos com uma lista de eventos já avaliados para esse processo.

FERREIRA, F. S.; ALVES, C. F.; CAVALCANTI, R. C.

R-BPM: Uma Metodologia para Gerenciamento de Processos de Negócios Consciente dos Riscos

isys | Revista Brasileira de Sistemas de Informação, Rio de Janeiro, vol. 9, No. 4, pp. 05-37, 2016 


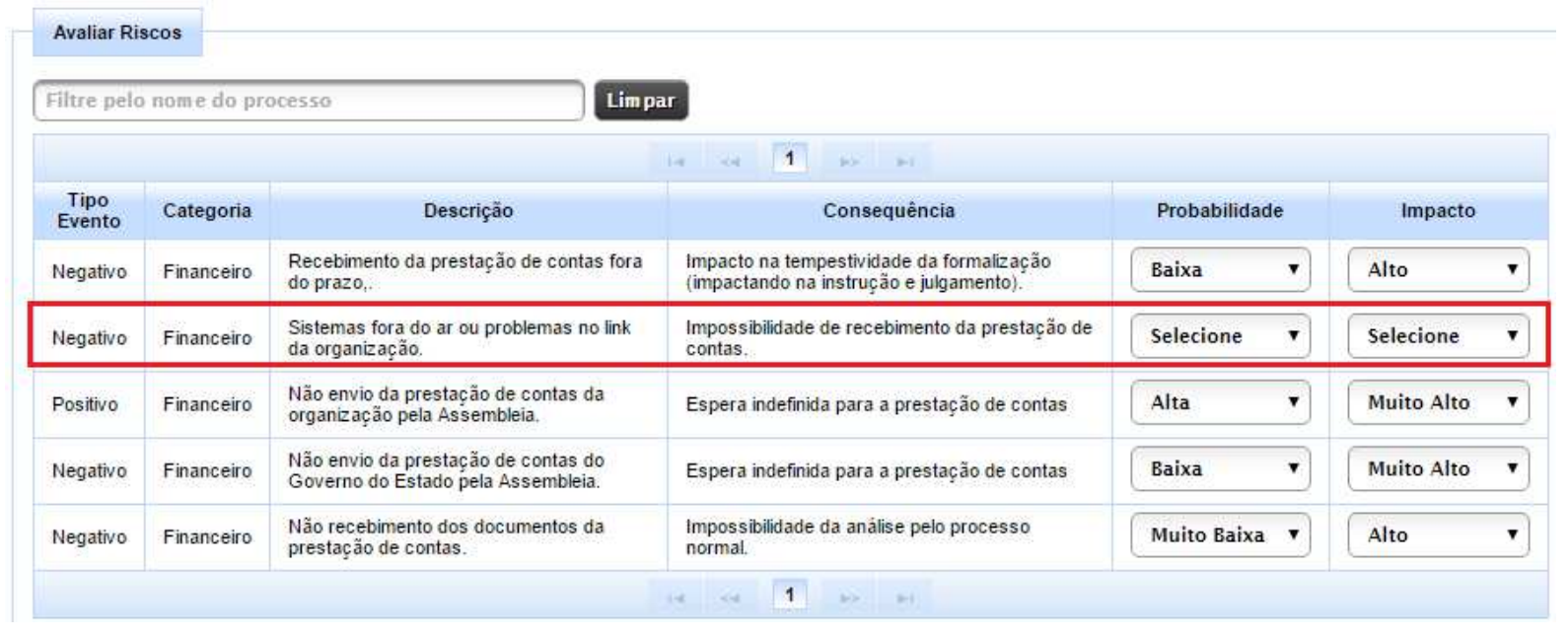

Figura 9. Avaliando riscos na ferramenta R-BPM

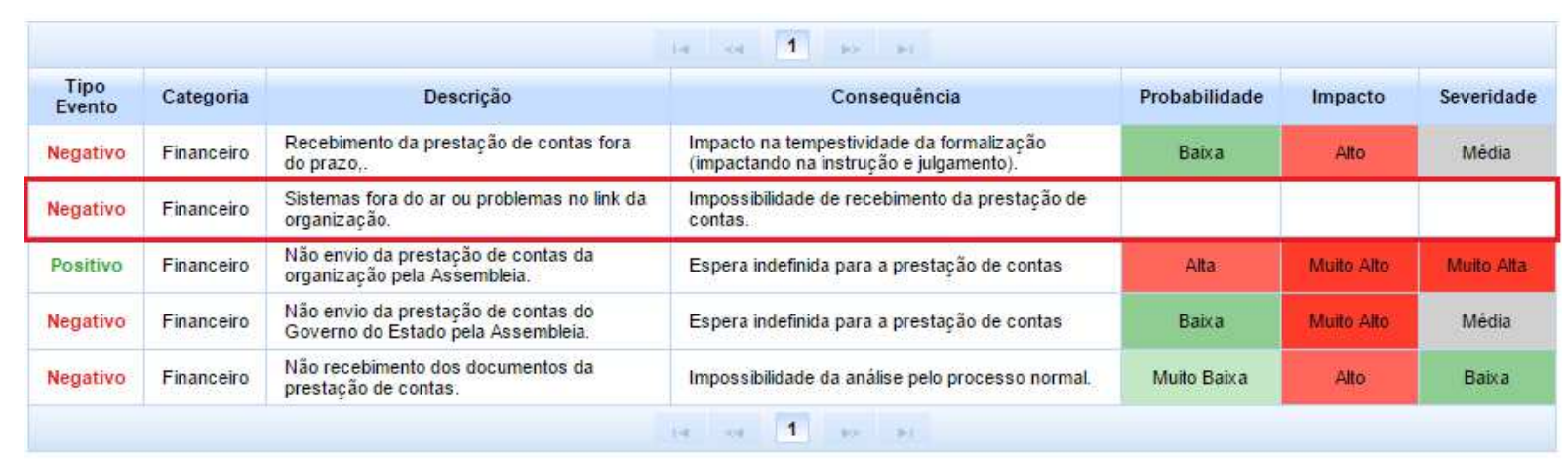

Figura 10. Mapa de Riscos com riscos avaliados

\subsection{Fase Desenho do Processo Proposto e Respostas aos Riscos}

A fase de Desenho do Processo Proposto e Respostas a Riscos tem como objetivo propor mudanças para solucionar os problemas encontrados nas etapas anteriores, sejam mudanças que visem a padronização dos processos, mudanças que reflitam na otimização de seu desempenho ou mudanças para tratamento dos riscos do processo. É necessário definir nessa etapa as respostas aos riscos de acordo com a tolerância e apetite aos riscos da organização. O COSO classifica as repostas a riscos nas categorias: Evitar, Reduzir, Compartilhar e Aceitar.

De acordo com a resposta escolhida para o risco, poderá ser necessário desenvolver um plano de implementação para executá-la. Uma parte crítica do plano de implementação é o estabelecimento de atividades de controle para assegurar-se de que a resposta ao risco seja conduzida [COSO, 2004]. Os indicadores de desempenho do processo também são criados/atualizados e aprovados nessa fase. Para apoiar a realização dessa etapa, a ferramenta de apoio da metodologia R-BPM permite definir as respostas aos riscos identificados e o responsável por cada risco. A Figura 11 ilustra a escolha do tratamento para um evento de risco do processo de prestação de contas utilizado como exemplo neste artigo. Já a Figura 12 mostra o mapa de gerenciamento de riscos com os tratamentos definidos para os eventos desse processo. 


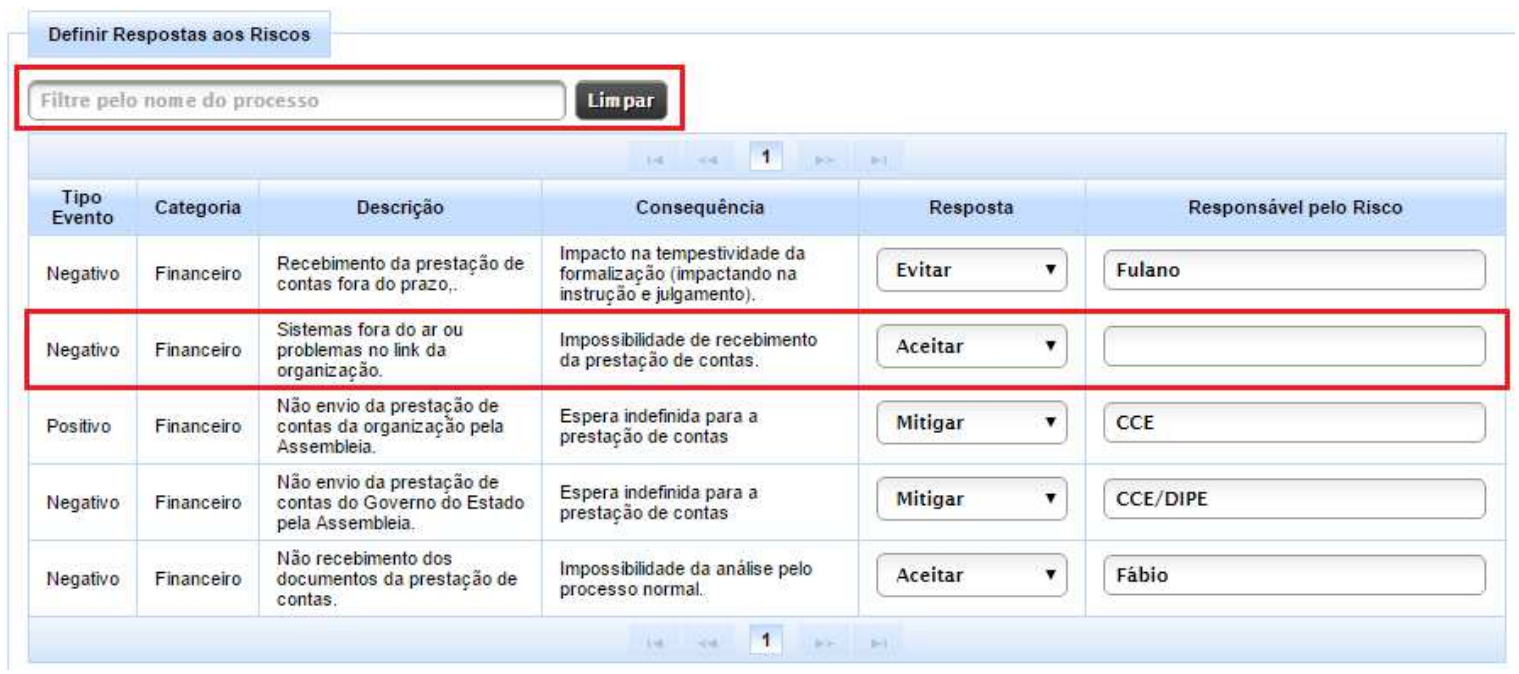

Figura 11. Definindo as respostas para os riscos na ferramenta R-BPM

\begin{tabular}{|c|c|c|c|c|c|c|c|c|}
\hline & & & $\Leftrightarrow$ & $=1$ & & & & \\
\hline $\begin{array}{l}\text { Tipo } \\
\text { Evento }\end{array}$ & Categoria & Descrição & Consequència & Probabilidade & Impacto & Severidade & Resposta & Responsâvel \\
\hline Negativo & Financeiro & $\begin{array}{l}\text { Recebimento da prestação } \\
\text { de contas fora do prazo,. }\end{array}$ & $\begin{array}{l}\text { Impacto na tempestividade da } \\
\text { formalização (impactando na } \\
\text { instruçẫo e julgamento). }\end{array}$ & Baixa & Alto & Média & Evitar & Fulano \\
\hline Negativo & Financeiro & $\begin{array}{l}\text { Sistemas fora do ar ou } \\
\text { problemas no link da } \\
\text { organizaçâa. }\end{array}$ & $\begin{array}{l}\text { Impossibilidade de recebimento } \\
\text { da prestação de contas. }\end{array}$ & Muito Baixa & Alto & Baixa & Mitigar & Maria \\
\hline Positivo & Financeiro & $\begin{array}{l}\text { Não envio da prestação de } \\
\text { contas da organizaçấo pela } \\
\text { Assembleia. }\end{array}$ & $\begin{array}{l}\text { Espera indefinida para a } \\
\text { prestaçãa de contas }\end{array}$ & Alta & Muito Alto & Muito Alta & Mitigar & CCE \\
\hline Negativo & Financeiro & $\begin{array}{l}\text { Não envio da prestação de } \\
\text { contas do Governo do } \\
\text { Estado pela Assembleia. }\end{array}$ & $\begin{array}{l}\text { Espera indefinida para a } \\
\text { prestaçãa de contas }\end{array}$ & Baixa & Muito Alto & Mèdia & Mitigar & CCEIDIPE \\
\hline
\end{tabular}

Figura 12. Mapa de Riscos com respostas definidas para os riscos

\subsection{Fase Implementação do Processo e Atividades de Controle}

Nessa fase são executadas as atividades necessárias para operacionalizar o processo proposto na fase anterior (TO BE). Essa fase também inclui a implementação de políticas e procedimentos novos ou revisados, incluindo procedimentos que asseguram que as respostas aos riscos sejam executadas. É necessário a elaboração de um plano de implementação contendo as ações necessárias para a implementação, os responsáveis e a definição de planejamento de custo. Além disso, o plano de implementação deve conter as políticas e os procedimentos (ações de controle) necessários para assegurar que as respostas aos riscos sejam executadas em caso de concretização de algum risco durante a execução do processo. Para apoiar a realização dessa fase, a ferramenta de apoio da metodologia R-BPM permite cadastrar ações de controle e definir estados de alerta (gatilhos) para os riscos identificados. Como uma ação pode ser comum a mais de um risco, é possível associar uma mesma ação a mais de um risco. A Figura 13 ilustra o cadastro de uma ação.

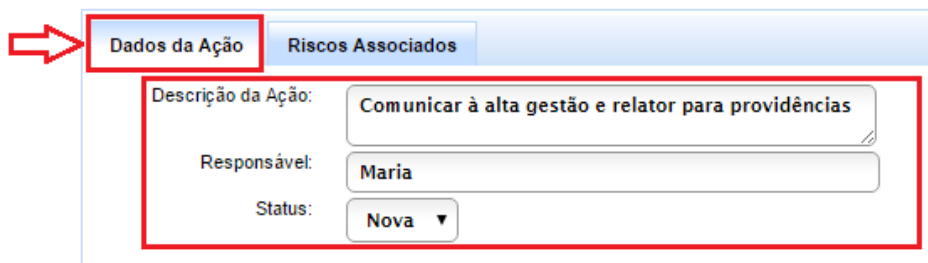

Figura 13. Definindo os dados da ação de controle (aba Dados da Ação)

FERREIRA, F. S.; ALVES, C. F.; CAVALCANTI, R. C.

R-BPM: Uma Metodologia para Gerenciamento de Processos de Negócios Consciente dos Riscos

isys | Revista Brasileira de Sistemas de Informação, Rio de Janeiro, vol. 9, No. 4, pp. 05-37, 2016 


\subsection{Fase Monitoramento e Controle do Processo e Monitoramento dos Riscos}

Essa fase tem como objetivo identificar o desempenho do processo e tornar possível a sua melhoria, além de monitorar o processo de gerenciamento de riscos e realizar as modificações necessárias. O monitoramento do processo inicia com a medição do desempenho e da conformidade do processo. Caso o desempenho do processo esteja atendendo às metas estabelecidas, o desempenho pode ser reportado para a organização. Caso contrário, deve-se buscar evidências para os problemas encontrados e posteriormente buscar as soluções. Essas soluções são convertidas em ações, que devem ser executadas em curto prazo. Para apoiar a realização dessa etapa, a ferramenta permite acompanhar as ações definidas na fase anterior e definir e acompanhar indicadores. A Figura 14 ilustra o registro do acompanhamento de uma ação definida para riscos do processo de prestação de contas e a Figura 15 ilustra uma lista de ações e o status de cada uma. Já a Figura 16 mostra o acompanhado de indicadores.

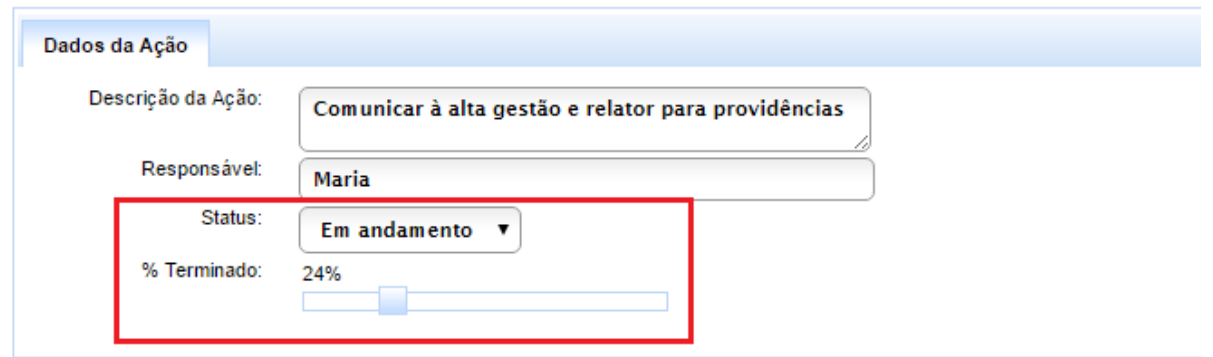

Figura 14. Acompanhando as ações de controle

\begin{tabular}{|c|c|c|c|c|c|}
\hline & ife $1 \times 1$ & & & & \\
\hline Descriçāo da Ação & Riscos Associados & Responsável & $\%$ Terminado & Status & Açồes \\
\hline Comunicar fechamento do risco & $\begin{array}{l}\text { 1. Não envio da prestação de contas da organização pela } \\
\text { Assembleia. } \\
\text { 2. Sistemas fora do ar ou problemas no link da organização. } \\
\text { 3. Recebimento da prestação de contas fora do prazo, }\end{array}$ & Pedro & $20 \%$ & $\begin{array}{l}\text { Em } \\
\text { andamento }\end{array}$ & 国证 \\
\hline Comunicar fechamento do risco & $\begin{array}{l}\text { 1. Recebimento da prestação de contas fora do prazo, } \\
\text { 2. Não recebimento dos documentos da prestaçăo de contas. }\end{array}$ & Fulano de Tal & $77 \%$ & $\begin{array}{l}\text { Em } \\
\text { andamento }\end{array}$ & E亚 \\
\hline $\begin{array}{l}\text { Comunicar à alta gestão e relator para } \\
\text { providências }\end{array}$ & $\begin{array}{l}\text { 1. Não envio da prestação de contas da organizaçầo pela } \\
\text { Assembleia. } \\
\text { 2. Não envio da prestação de contas do Governo do Estado pela } \\
\text { Assembleia. }\end{array}$ & Maria & $24 \%$ & $\begin{array}{l}\text { Em } \\
\text { andamento }\end{array}$ & 8 佂 \\
\hline
\end{tabular}

Figura 15. Listagem de ações com status atualizado

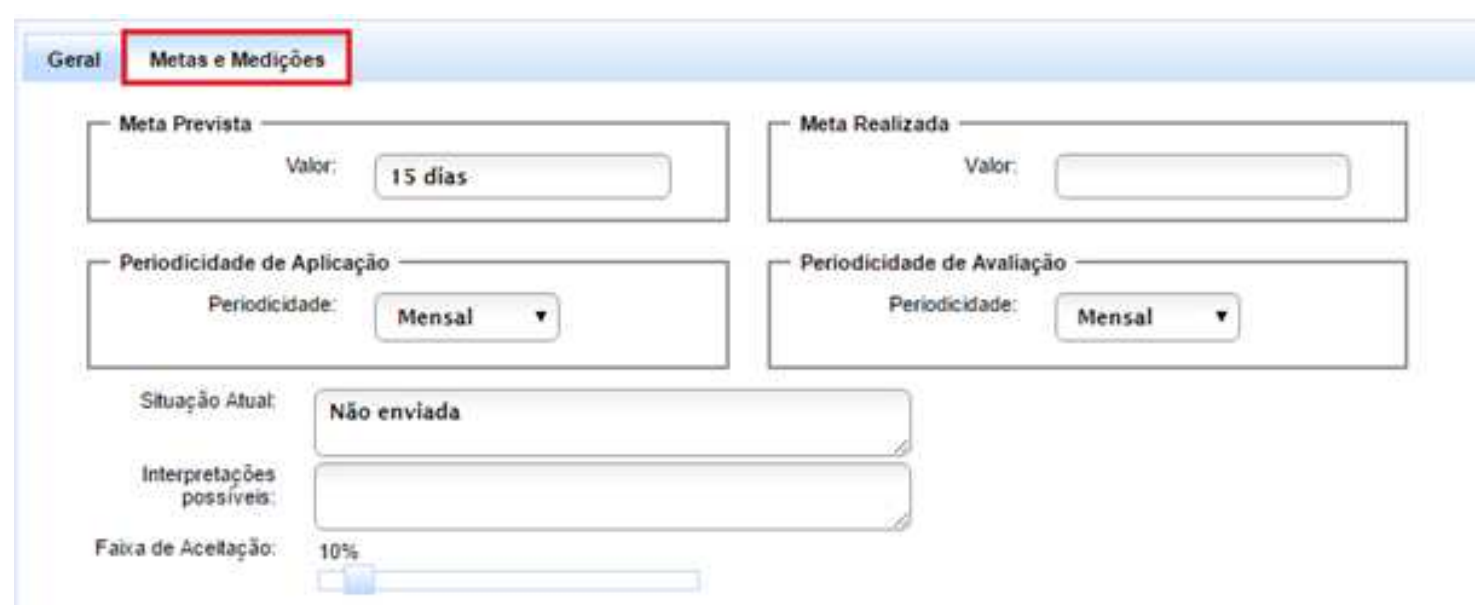

Figura 16. Acompanhamento de Indicadores (Aba Metas e Medições)

FERREIRA, F. S.; ALVES, C. F.; CAVALCANTI, R. C.

R-BPM: Uma Metodologia para Gerenciamento de Processos de Negócios Consciente dos Riscos

isys | Revista Brasileira de Sistemas de Informação, Rio de Janeiro, vol. 9, No. 4, pp. 05-37, 2016 


\subsection{Fase Informações e Comunicações}

A comunicação ágil e adequada com as diversas partes interessadas, acionistas, reguladores, analistas financeiros e outras entidades externas tem a finalidade de permitir avaliações mais rápidas e objetivas a respeito dos riscos a que está exposta a organização [IBGC, 2007]. A comunicação pode surgir sob a forma de manuais de políticas, memorandos, mensagens de correio eletrônico, notificações em quadros de avisos, mensagens pela Internet e mensagens gravadas em vídeo [COSO, 2004]. O importante é que seja verificada a qualidade da informação antes de divulga-la, uma vez que dados imprecisos podem gerar riscos não identificados. De acordo com o COSO (2004), para assegurar a qualidade das informações é necessário verificar se:

○ O conteúdo é apropriado - está no nível de detalhes adequado?

○ As informações são oportunas - estarão disponíveis quando necessário?

○ As informações são atuais - são as mais recentes?

○ As informações são exatas - os dados estão corretos?

○ As informações são de fácil acesso - são de fácil obtenção por aqueles que as necessitam?

É importante que todo o pessoal receba uma mensagem clara da alta administração, alertando que as responsabilidades do gerenciamento de riscos devem ser levadas a sério e que cada um deve entender a sua própria função no gerenciamento de riscos, assim como as atividades individuais que se relacionam com o trabalho dos demais.

\section{Estudo de Caso}

Esta seção descreve os resultados obtidos com a realização do estudo de caso em uma organização do setor público, na qual coletaram-se as percepções de especialistas e praticantes das áreas de riscos e de BPM sobre a metodologia e a ferramenta.

\subsection{Objetivos do Estudo de Caso}

O principal objetivo do estudo de caso foi a avaliação e refinamento da metodologia RBPM na organização estudada como estratégia da DSR. Portanto, o estudo de caso teve um caráter descritivo das avaliações e, como a abordagem de pesquisa DSR envolve um ciclo contínuo de construção e avaliação, teve também um caráter de melhoria da própria metodologia através dos refinamentos. Os critérios utilizados para a avaliação da metodologia foram definidos com base nos critérios utilizados na Fase 1 para analisar os trabalhos relacionados, que foram:

- Critério 1: presença de atividades relacionadas à gestão de riscos em todas as fases do ciclo de vida BPM.

- Critério 2: presença das principais atividades de gerenciamento de riscos.

- Critério 3: compartilhamento das atividades que são comuns ao gerenciamento de riscos e BPM.

- Critério 4: compartilhamento da responsabilidade pelos riscos para os responsáveis pelos processos.

A partir destes critérios, foi possível avaliar a metodologia com especialistas e também compará-la com os trabalhos relacionados apresentados na Seção 2.4. 


\subsection{Desenvolvimento do Estudo de Caso}

Para a aplicação da metodologia na organização estudada foi selecionado o processo de prestação de contas da organização. Esse processo tinha como objetivos:

1. Receber os processos originários e recursos da prestação de contas conforme legislação;

2. Analisar a lisura dos gastos públicos em cumprimento à legislação, do ponto de vista de gestão (responsabilidade administrativa) e de governo (responsabilidade política).

Ao todo foram mapeados 24 riscos para o processo de prestação de contas da organização. O mapeamento dos riscos desse processo teve início em setembro de 2015 e término em maio de 2016, e a utilização da ferramenta de apoio aconteceu somente no mês de maio de 2016. O grupo focal foi escolhido como estratégia a ser utilizada para coletar os dados das avaliações da metodologia R-BPM. Ao todo foram realizados 3 grupos focais de duração média de 50 minutos cada e com uma média de 7 a 8 participantes. As discussões foram realizadas, assim como na fase 2, com especialistas das áreas de riscos e de BPM da organização estudada, além de pesquisadores da área. Participaram dos grupos focais 2 especialistas em riscos, 3 especialistas em BPM e 2 pesquisadores. A Seção 5.3 apresenta os resultados dos grupos focais realizados durante a construção da metodologia e a Seção 5.4 apresenta os resultados do último grupo focal, realizado com a metodologia e a ferramenta praticamente prontas.

\subsection{Resultados dos Grupos Focais Preliminares}

De posse dos resultados da análise dos principais trabalhos relacionados existentes na literatura e suas limitações e da abordagem de gerenciamento de riscos escolhida, foi elaborado um esboço da metodologia para permitir realizar o gerenciamento de riscos em processos de negócios de forma integrada com o ciclo de vida BPM. Para a versão inicial da metodologia foi feito um agrupamento de cada atividade comum a toda abordagem de gerenciamento de riscos com a fase do ciclo de vida BPM com que cada uma dessas atividades possui maior relação. O objetivo desse agrupamento foi a execução das atividades de gerenciamento de riscos e das fases do ciclo de vida BPM de forma conjunta como sendo uma coisa única, assim, o que era executado duas vezes de forma isolada, agora seria executado apenas uma. A partir dessa versão inicial iniciou-se o estudo de caso para avaliação e refinamento da metodologia, além da aplicação desta no mundo real.

No primeiro grupo focal foi feita, como estímulo inicial da discussão, uma breve apresentação da versão inicial da metodologia R-BPM. A partir de então, iniciou-se o ciclo de refinamento da metodologia com os resultados das avaliações realizadas no grupo focal. Como a organização estudada já adotava o gerenciamento de riscos e BPM de forma isolada, foi possível conhecer também, através do grupo focal, a forma como as atividades de gerenciamento de riscos e de BPM eram realizadas na organização, o que permitiu repensar como essas atividades seriam agrupadas. Por exemplo, o componente de Informações e Comunicações estava agrupado com a fase de implementação do ciclo de vida BPM. Através de opiniões identificadas nas falas dos participantes, foi feito o posicionamento desse componente no centro da metodologia, 
pois podemos, o tempo todo e durante qualquer fase do ciclo, identificar informações relevantes e comunicá-las na forma e no prazo que permitam aos responsáveis tomar as devidas providências. Essa evidência pode ser identificada na seguinte fala de um dos participantes da reunião especialista em BPM:

"A informação deve chegar o mais rápido possível ao destinatário, não podemos esperar uma fase para comunicá-la..."

Foi possível também confirmar outros agrupamentos, como o caso da fase de Monitoramento e Controle do processo e Monitoramento dos Riscos:

"O monitoramento dos processos, ele engloba o monitoramento de riscos também...” (Especialista em riscos)

Esse processo se repetiu e a metodologia foi sendo aprimorada de forma iterativa e incremental. A metodologia R-BPM apresentada na Seção 4 representa a versão final e o resultado de um trabalho onde pesquisadores e especialistas das áreas de riscos e de BPM puderam discutir a problemática de pesquisa até chegar nessa versão.

\subsection{Resultados do Grupo Focal de Avaliação}

O grupo focal contou com 7 participantes selecionados de maneira intencional, conforme os objetivos da análise, de forma a criar um grupo propício à discussão. Os critérios utilizados para avaliação da metodologia foram os descritos na Seção 5.2. Além disso, as seguintes questões foram utilizadas para direcionar a discussão do grupo focal:

- Q1 - Quais são as vantagens de gerenciar riscos em processos de negócios de forma integrada com BPM?

○ Q2 - Como a metodologia R-BPM pode melhorar a gestão de processos de negócios?

- Q3 - Quais são os principais benefícios da metodologia $R-B P M$ e de sua ferramenta de apoio?

- Q4 - Quais são as principais limitações da metodologia R-BPM e de sua ferramenta de apoio.

Com relação ao Critério 1: presença de atividades relacionadas à gestão de riscos em todas as fases do ciclo de vida BPM, foi possível constatar que esse é um grande benefício da metodologia, conforme relato de um dos participantes especialista em riscos:

"Um grande benefício da metodologia é a integração da visão de riscos de ponta a ponta no ciclo de vida BPM...”.

Alguns participantes também destacaram a vantagem do compartilhamento de recursos e atividades proporcionado pela metodologia, conforme buscava avaliar o Critério 3: compartilhamento das atividades que são comuns ao gerenciamento de riscos e BPM.

"Uma vantagem é a automação da gestão de riscos em projetos de $B P M$, sem necessidade de geração de mais artefatos, com disponibilidade dos dados online e de forma fácil..." (Especialista em Riscos)

FERREIRA, F. S.; ALVES, C. F.; CAVALCANTI, R. C.

R-BPM: Uma Metodologia para Gerenciamento de Processos de Negócios Consciente dos Riscos

isys | Revista Brasileira de Sistemas de Informação, Rio de Janeiro, vol. 9, No. 4, pp. 05-37, 2016 
"Através da utilização da metodologia temos otimização de recursos, visão integrada e holística, possibilidade de monitoramento...” (Especialista em BPM)

Com relação ao Critério 2: presença das principais atividades de gerenciamento de riscos, foram mencionadas algumas características da metodologia pelos participantes.

"A metodologia permite a identificação de riscos e o tratamento adequado, compatível com as expectativas da organização, bem como o monitoramento das ações de tratamento..." (Especialista em Riscos)

“... é possível mapear os riscos e gerenciar as ações para evitálos..." (Especialista em BPM)

Algumas vantagens citadas pelos participantes foram:

"Como está alinhada ao ciclo BPM, conseguimos que os ricos sejam tratados de forma integrada e não isoladamente.

"Pra gente que trabalha com o controle interno como um todo, é interessante quando você vai auditar um processo que você veja no que aquele processo reflete ou se preocupa com os riscos da corporação..." (Especialista em riscos)

Não foram identificadas limitações na realização do grupo focal, no entanto, uma melhora na descrição das fases da metodologia e das funcionalidades da ferramenta foi sugerida:

"Talvez a descrição de algumas etapas possa ser melhorada, já que a ênfase está no uso da ferramenta e não na definição completa (incluindo exemplos) do que estamos cadastrando (ex. categorias, eventos, etc.) e do porquê de estarmos realizando aquela atividade na ferramenta..."

A realização do grupo focal contribuiu para avaliação da metodologia e da ferramenta de apoio e foi útil para ajudar a responder as questões desta pesquisa. No entanto, foram poucas as contribuições para melhoria.

\subsection{Resultados do Questionário de Avaliação}

Um questionário fundamentado no modelo de aceitação de tecnologia (Technology Acceptance Model - TAM) (DAVIS, 1989) também foi utilizado para avaliação da metodologia. O público alvo dos questionários foram pesquisadores e especialistas em BPM (6 no total) e os critérios utilizados para avaliação, tanto da metodologia quanto da ferramenta, foram a facilidade de uso percebida e a utilidade percebida de acordo com o modelo TAM, além dos critérios descritos na Seção 5.2 para a estratégia de avaliação adotada no estudo de caso.

Com relação ao Critério 1, foi possível comprovar que existe a presença de atividades de gerenciamento de riscos em todas as fases do ciclo de vida BPM, e que as atividades que são comuns a todo modelo de gerenciamento de riscos também são 
percebidas na metodologia, atendendo ao Critério 2. Conforme ilustrado nas Figuras 17 e 18, houve concordância total entre os participantes com relação aos dois critérios.

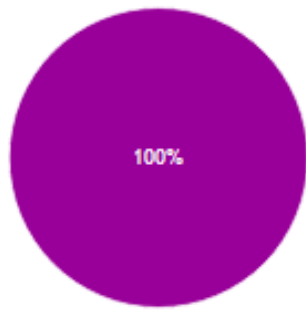

- Năo concordo totalmente

- Năo concordo parcialmente

- Indiferente

Concordo parcialmente

- Concordo totalmente

Figura 17. A metodologia R-BPM permite que sejam realizadas atividades de gerenciamento de riscos em todas as fases do ciclo de vida BPM.

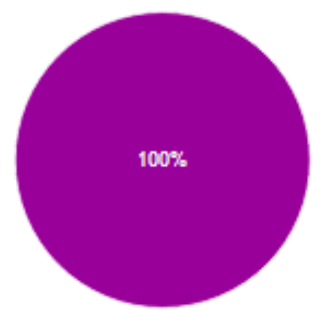

- Nắo concordo totalmente

- Năo concordo parcialmente

Indiferente

- Concordo parcialmente

Concordo totalmente

Figura 18. A metodologia R-BPM permite que sejam realizadas no ciclo de vida BPM as atividades comuns de gerenciamento de riscos.

Com relação ao Critério 3, apesar da maioria dos respondentes concordar que existe o reaproveitamento das atividades de ambos os contextos, uma otimização dessas pode ser buscada para melhorar esse quesito conforme ilustrado na Figura 19.
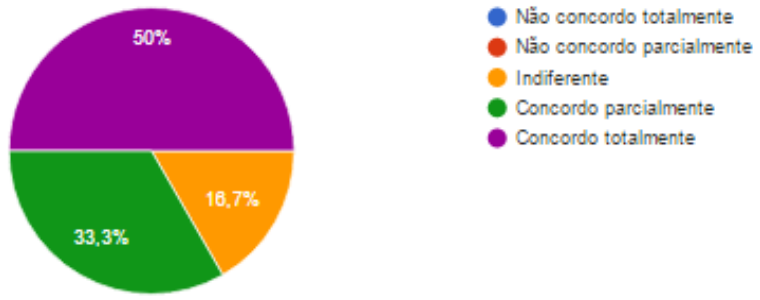

Figura 19. A metodologia R-BPM permite que as atividades comuns ao gerenciamento de risco e ao gerenciamento de processos de negócios sejam aproveitadas de forma otimizada.

A avaliação mostra também que é possível descentralizar a responsabilidade pelos riscos para os donos dos processos, de acordo com o Critério 4. A Figura 20 ilustra esse questionamento.
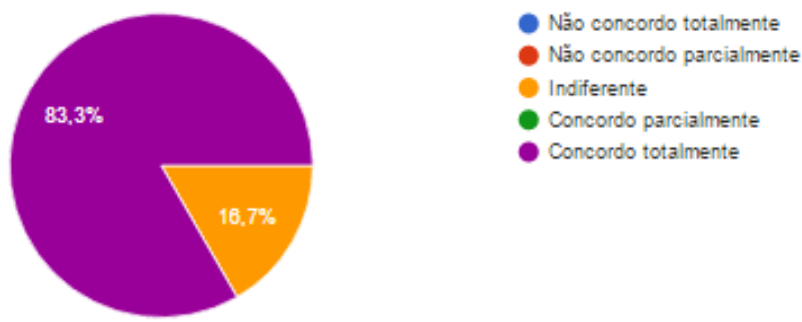

Figura 20. A metodologia R-BPM permite que a responsabilidade pelos riscos seja compartilhada com os analistas e/ou responsáveis pelo processo. 
Além dos critérios analisados acima, foram consideradas também a Facilidade de Uso Percebida e a Utilidade Percebida para a metodologia R-BPM e sua ferramenta de apoio através do Modelo de Aceitação de Tecnologia (TAM) utilizado nos questionários. Quanto a facilidade de uso percebida foi possível constatar que, apesar da clareza dos artefatos e procedimentos da metodologia e de esses serem suficientes para utilização da mesma, pode ser necessário um treinamento para a sua utilização, conforme ilustrado na Figura 21.
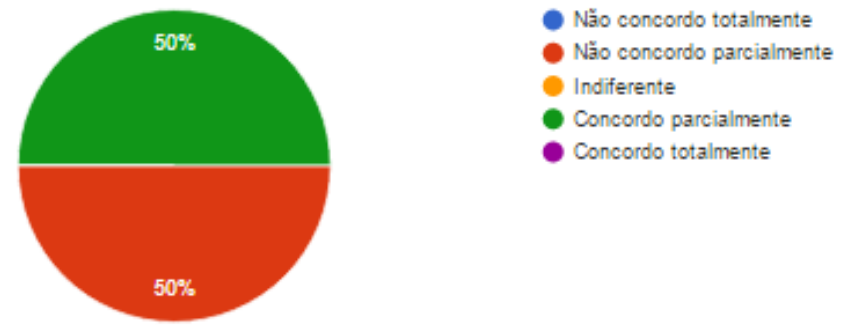

Figura 21. É necessário treinamento para utilizar a metodologia R-BPM

No entanto, a ferramenta pode auxiliar no preenchimento dessa lacuna, já que ela foi considerada como um importante artefato da metodologia e de fácil utilização conforme ilustrado na Figura 22.
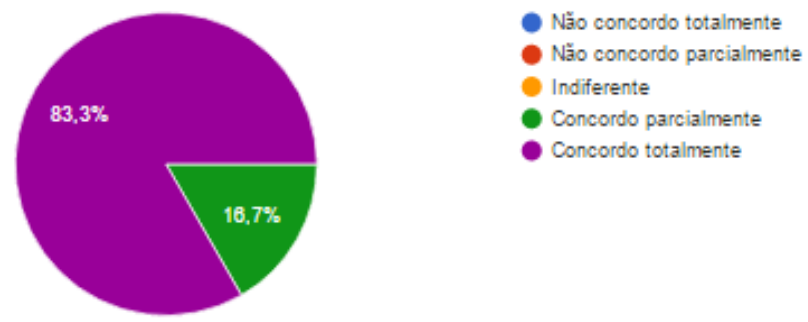

Figura 22. Aprender a utilizar a ferramenta é fácil

Com relação à utilidade percebida, foi possível constatar que a metodologia contribui para a organização alcançar os objetivos relacionados à gestão por processos e obter agilidade na identificação e tratamento de riscos. Contribui também para obter uma visão integrada dos riscos durante cada etapa do ciclo de vida BPM e descentralizar a responsabilidade pelos riscos.

Já a ferramenta, contribui para: agilizar a execução das atividades da metodologia R-BPM; ter uma visão geral sobre os riscos dos processos de negócios; controlar e acompanhar os riscos; priorizar os riscos; e monitorar melhor as ações para tratamento dos riscos.

Maiores detalhes sobre os questionários aplicados e as questões que motivaram as discussões nos grupos focais podem ser consultados em https://sites.google.com/a/cin.ufpe.br/modelo-r-bpm/.

\subsection{Comparação com os Trabalhos Relacionados}

Os critérios utilizados para avaliar a metodologia através dos grupos focais e do questionário, foram definidos com base nos critérios utilizados para analisar os trabalhos relacionados descritos na literatura e apresentados na Seção 2.4. Os resultados obtidos nessa avaliação permitiram comparar a metodologia R-BPM com os trabalhos FERREIRA, F. S.; ALVES, C. F.; CAVALCANTI, R. C.

R-BPM: Uma Metodologia para Gerenciamento de Processos de Negócios Consciente dos Riscos

isys | Revista Brasileira de Sistemas de Informação, Rio de Janeiro, vol. 9, No. 4, pp. 05-37, 2016 
relacionados. Com relação ao Critério 1: presença de atividades relacionadas à gestão de riscos em todas as fases do ciclo de vida BPM, foi possível comprovar através dos grupos focais e do questionário de avaliação da metodologia que existe a presença de atividades de gerenciamento de riscos em todas as fases do ciclo de vida BPM. A Tabela 7 mostra a comparação entre a metodologia R-BPM e os trabalhos relacionados com relação ao critério 1 .

Tabela 7. Comparação entre a metodologia R-BPM e os trabalhos relacionados com relação à presença de atividades relacionadas à gestão de riscos nas fases do ciclo de vida BPM

\begin{tabular}{|c|c|c|c|c|c|c|}
\hline Cód. & Planejamento & Modelagem & Análise & Desenho & Implementação & Monitoramento \\
\hline P01 & & $\mathrm{X}$ & & & & \\
\hline P02 & & $\mathrm{X}$ & $\mathrm{X}$ & $\mathrm{X}$ & & \\
\hline P03 & & $\mathrm{X}$ & & & & \\
\hline P04 & & $\mathrm{X}$ & $\mathrm{X}$ & $\mathrm{X}$ & & \\
\hline P05 & & $\mathrm{X}$ & $\mathrm{X}$ & $\mathrm{X}$ & & \\
\hline P06 & & & $\mathrm{X}$ & $\mathrm{X}$ & & \\
\hline P07 & & & $\mathrm{X}$ & & $\mathrm{X}$ & \\
\hline P08 & & & & $\mathrm{X}$ & $\mathrm{X}$ & \\
\hline P09 & & & & & & $\mathrm{X}$ \\
\hline P10 & & $\mathrm{X}$ & $\mathrm{X}$ & $\mathrm{X}$ & $\mathrm{X}$ & $\mathrm{X}$ \\
\hline P11 & & $\mathrm{X}$ & $\mathrm{X}$ & $\mathrm{X}$ & $\mathrm{X}$ & $\mathrm{X}$ \\
\hline P12 & & $\mathrm{X}$ & & & & \\
\hline R-BPM & & &
\end{tabular}

Também podemos perceber isso no relato de um dos participantes do grupo focal:

"Um grande benefício da metodologia é a integração da visão de riscos de ponta a ponta no ciclo de vida BPM...”.

Já com relação ao Critério 2: presença das principais atividades de gerenciamento de riscos, foi possível constatar através dos grupos focais e do questionário de avaliação da metodologia que as atividades que são comuns a toda abordagem de gerenciamento de riscos também são percebidas na metodologia. Podemos perceber isso através da questão 14 do questionário (Figura 23):

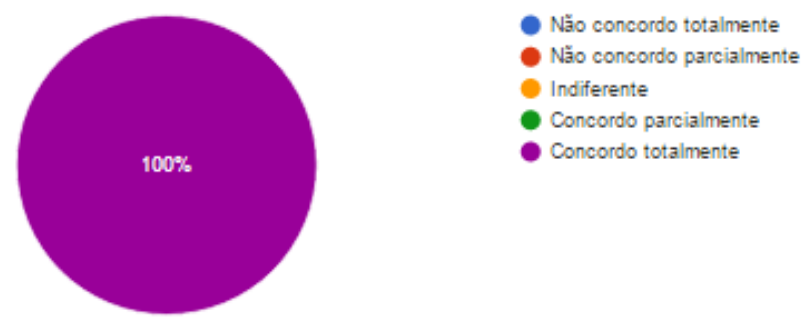

Figura 23 - A metodologia R-BPM permite que sejam realizadas no ciclo de vida $B P M$ as atividades comuns de gerenciamento de riscos.

A Tabela 8 mostra a comparação entre a metodologia R-BPM e os trabalhos relacionados com relação às atividades de gerenciamento de riscos e às abordagens de gerenciamento de riscos consagradas. 
Tabela 8. Comparação entre a metodologia R-BPM e os trabalhos relacionados com relação às atividades de gerenciamento de riscos.

\begin{tabular}{|c|c|c|c|c|c|c|c|}
\hline \multirow{2}{*}{ Cód. } & \multicolumn{2}{|c|}{ Identificação de Riscos } & \multicolumn{2}{|c|}{ Análise de Riscos } & Respostas \\
\cline { 2 - 8 } & $\begin{array}{c}\text { Identificação } \\
\text { de Riscos }\end{array}$ & $\begin{array}{c}\text { Anotação } \\
\text { de Riscos }\end{array}$ & Probabilidade & Impacto & $\begin{array}{c}\text { Atividades } \\
\text { de Controle }\end{array}$ & $\begin{array}{c}\text { Abordagem } \\
\text { de Riscos }\end{array}$ \\
\hline P01 & $\mathrm{X}$ & $\mathrm{X}$ & & & $\mathrm{X}$ & $\mathrm{X}$ & COSO \\
\hline P02 & $\mathrm{X}$ & $\mathrm{X}$ & & & & $\mathrm{X}$ & \\
\hline P03 & & $\mathrm{X}$ & & & & $\mathrm{X}$ & \\
\hline P04 & & $\mathrm{X}$ & & & & & Basiléia II \\
\hline P05 & $\mathrm{X}$ & $\mathrm{X}$ & & & & & \\
\hline P06 & $\mathrm{X}$ & & & $\mathrm{X}$ & & & COSO \\
\hline P07 & $\mathrm{X}$ & & & $\mathrm{X}$ & & & NIST 800-30 \\
\hline P08 & & & $\mathrm{X}$ & $\mathrm{X}$ & $\mathrm{X}$ & & \\
\hline P09 & & $\mathrm{X}$ & $\mathrm{X}$ & & & & $\mathrm{M}$ O_R \\
\hline P10 & $\mathrm{X}$ & $\mathrm{X}$ & $\mathrm{X}$ & $\mathrm{X}$ & $\mathrm{X}$ & & \\
\hline P11 & $\mathrm{X}$ & & $\mathrm{X}$ & & & & \\
\hline P12 & $\mathrm{X}$ & & & & & & COSO \\
\hline R-BPM & $\mathrm{X}$ & & $\mathrm{X}$ & $\mathrm{X}$ & $\mathbf{X}$ & $\mathbf{X}$ & \\
\hline
\end{tabular}

Maiores detalhes sobre os trabalhos utilizados na comparação podem ser encontrados na Tabela 2.

\section{Conclusões}

\subsection{Resultados Obtidos}

Este artigo apresentou como principal resultado da pesquisa a metodologia R-BPM que permite realizar o gerenciamento de riscos em processos de negócios de forma integrada com o ciclo de vida BPM. Para tal, a metodologia utiliza a estrutura de gerenciamento de riscos do COSO e o ciclo de vida BPM proposto por Oliveira (2014).

O objetivo específico de analisar as abordagens propostas na literatura de gerenciamento de riscos em processos de negócios buscou responder à (QP1): Quais são as abordagens existentes para gerenciar riscos de forma integrada com BPM e suas limitações? Com relação a esse objetivo, foi constatado que, apesar do número crescente de pesquisas sobre o tema, a maioria das abordagens existentes não é aplicada à todas as fases do ciclo de vida BPM e/ou não tiveram aplicações práticas. A única abordagem analisada que é aplicada a todas as fases do ciclo possui apenas a atividade de identificação de riscos. Esse é um outro problema dos trabalhos analisados, não há a presença das atividades geralmente necessárias à gestão de riscos. Consequentemente, existe uma lacuna para trabalhos que permitam integrar abordagens de gerenciamento de riscos consagradas no contexto de BPM e que este estudo visa suprir.

O objetivo específico de analisar as abordagens de gerenciamento de riscos existentes e identificar a mais adequada para ser integrada com BPM buscou responder à (QP2): Qual é o modelo de gerenciamento de riscos mais adequado para ser integrado com BPM? Referente a esse objetivo, foi constatado que os modelos analisados possuem atividades semelhantes e que o que difere entre eles é o foco de cada um. Como a SEC (Securities and Exchange Commission), responsável pela implantação da lei Sarbanes-Oxley (SOX), cita o COSO como a estrutura de gerenciamento de riscos 
mais recomendada, ele tem sido a estrutura mais adotada pelas organizações e foi escolhido também para ser utilizado neste trabalho. A justificativa dessa escolha se deve ao enfoque de gestão corporativa do modelo COSO. Essa visão é alinhada com a perspectiva de BPM. Além disso, a maioria dos trabalhos analisados que utiliza alguma abordagem de risco adota o COSO, os que não adotam são aplicados a domínios específicos de riscos, como é o caso do trabalho de Weiss e Winkelmann (2011), que foi desenvolvido no domínio financeiro e por isso é baseado no Acordo de Basiléia II.

Os objetivos específicos de elaborar uma metodologia que permita realizar o gerenciamento de riscos em processos de negócios de forma integrada com o ciclo de vida BPM e construir uma ferramenta de software para apoiá-la, buscaram responder à (QP3): Como gerenciar riscos em processos de negócios de forma integrada com o ciclo de vida BPM? Com relação a esse objetivo, foi proposta a metodologia R-BPM e desenvolvida uma ferramenta web para apoiá-la. A metodologia R-BPM permite que sejam realizadas atividades de gerenciamento de riscos durante todo o ciclo de vida BPM. Com a ferramenta de software construída para apoiá-la é possível tornar a sua implantação mais simples e fácil, além de agilizar a execução de suas atividades.

Para atingir o objetivo de avaliar a metodologia proposta e sua ferramenta de apoio em uma organização experiente em BPM, associado à (QP4) Quais são os principais benefícios em gerenciar riscos de processos de negócios de forma integrada com BPM? - foi realizado um estudo de caso da aplicação da metodologia em uma organização pública do estado de Pernambuco. O estudo de caso foi escolhido como estratégia de avaliação inserida na Design Science Research e mostrou que, embora seja possível realizar o gerenciamento de riscos em processos de negócios de forma isolada, fora do ciclo de vida BPM, a metodologia proposta neste artigo pode fornecer diversos benefícios. A metodologia R-BPM pode auxiliar, e até mesmo incentivar, organizações que já adotam BPM a gerenciar riscos em seus processos de negócios de forma otimizada, já que os recursos utilizados com BPM poderão ser compartilhados. É possível também obter uma maior eficiência de recursos humanos, agilidade na identificação e tratamento de riscos que podem afetar o sucesso de iniciativas de BPM, além de uma visão integrada dos riscos durante cada etapa do ciclo de vida BPM.

Além disso, com a adoção da metodologia R-BPM, a responsabilidade pelos riscos passa a ser compartilhada. Com isso, os analistas e/ou donos dos processos podem ter melhores condições para avaliar os riscos e tratá-los de forma efetiva, já que as atividades que são comuns a todo modelo de gerenciamento de riscos estão disponíveis na metodologia. Finalizando, o pensamento horizontal proporcionado por BPM, que enfatiza a visão ponta-a-ponta dos processos, torna-se um grande facilitador para aumentar a conscientização sobre os riscos de forma mais holística.

\subsection{Análise Crítica}

Dentre os critérios utilizados na Seção 2.4 para analisar os trabalhos relacionados na literatura, foi possível constatar que, com relação aos critérios analisados na Tabela 4, a metodologia R-BPM só não possui uma proposta de anotação para representar e comunicar os riscos. A principal causa disso foi o escopo do trabalho que pretendia cobrir todas as fases do ciclo de vida BPM com atividades comuns ao gerenciamento de riscos e, embora a representação de riscos através de modelos possa auxiliar na sua 
interpretação e comunicação, esta não é uma das atividades comuns. No entanto, quem for utilizar a metodologia R-BPM poderá suprir essa lacuna com a extensão da notação BPMN proposta por Cope et al. (2010), caso desejado.

Já com relação aos critérios analisados na Tabela 5, existe a presença de atividades de gerenciamento de riscos em todas as fases do ciclo de vida BPM, o que melhora a atenção sobre os mesmos já que durante todos os estágios de BPM existe um cuidado com a identificação e tratamento dos riscos. Uma questão que pode ser melhorada, entretanto, seria a adição de novas técnicas de avaliação de riscos à ferramenta R-BPM, principalmente quantitativa, já que esta oferece apenas uma opção de avaliação qualitativa.

A metodologia R-BPM possui atividades relacionadas ao gerenciamento de riscos em todas as fases do ciclo de vida BPM. No entanto, isso não significa que o tratamento dado aos riscos por ela em uma fase específica do ciclo seja melhor do que o dado por um outro trabalho que seja aplicado apenas à essa fase. Para chegar à essa conclusão é necessário um estudo detalhado, fazendo o comparativo de fase por fase, que não foi o objetivo deste trabalho, já que estávamos interessados em cobrir o ciclo como um todo.

\subsection{Trabalhos Futuros}

Como trabalho futuro, recomendamos que a avaliação da metodologia seja feita em outras organizações públicas e privadas. Dessa forma será possível validar se as características aqui apresentadas se aplicam aos diferentes cenários das organizações. Recomendamos também que a metodologia seja usada por organizações que estejam iniciando suas ações com BPM, assim será possível avaliar as diferenças com relação às organizações que já utilizam BPM.

Recomendamos ainda pesquisas sobre notações de modelos de processos que permitam representar os riscos e possam ser utilizadas na metodologia R-BPM, visando facilitar a análise e comunicação dos riscos. Sugerimos também que funcionalidades não cobertas pela ferramenta sejam desenvolvidas, por exemplo, uma forma de realizar a análise quantitativa dos riscos ou rastreamento dos riscos por processo.

Apesar da metodologia R-BPM possuir atividades relacionadas ao gerenciamento de riscos em todas as fases do ciclo de vida BPM, isso não garante que as atividades propostas são melhores do que as propostas nos trabalhos que atuam apenas em algumas fases. Neste artigo, comparamos apenas a existência ou não de atividades de gestão de riscos em cada fase do ciclo de vida BPM. Portanto, para aprimoramento da metodologia, é importante que seja feita uma pesquisa para identificar se as atividades propostas em cada fase do ciclo de vida BPM para lidar com riscos são as melhores alternativas e o que pode ser melhorado em cada fase de acordo com os trabalhos existentes na literatura. Sugerimos por fim, que a metodologia seja constantemente atualizada de modo a suprir as deficiências não encontradas neste estudo.

\section{Referências}

ASSOCIAÇÃO BRASILEIRA DE NORMAS TÉCNICAS. (2009). NBR ISO 31000:

Gestão de riscos - Princípios e diretrizes (Tech. Rep.). Rio de Janeiro: ABNT.

FERREIRA, F. S.; ALVES, C. F.; CAVALCANTI, R. C.

R-BPM: Uma Metodologia para Gerenciamento de Processos de Negócios Consciente dos Riscos
isys | Revista Brasileira de Sistemas de Informação, Rio de Janeiro, vol. 9, No. 4, pp. 05-37, 2016 
ASSOCIATION OF BUSINESS PROCESS MANAGEMENT PROFESSIONALS. (2013). Guide for business process management: Common body of knowledge (Tech. Rep.). ABPMP.

Baldam, R. L. (2014). Gerenciamento de processos de negócios - BPM: uma referência para implantação prática (Primeira ed.). Rio de Janeiro: Elsevier.

Bax, M. P. (2013, Maio-Agosto). Design Science: filosofia da pesquisa em ciência da informação e tecnologia. Ciência da Informação, 42(2), 298 - 312.

Betz, S., Hickl, S., \& Oberweis, A. (2011, Setembro). Risk-Aware Business Process Modeling and Simulation Using XML Nets. In Commerce and enterprise computing (cec), 2011 IEEE 13th conference on (pp. 349 - 356). Luxemburgo: IEEE.

Committee of Sponsoring Organizations of the Treadway Commission. (2004). Enterprise Risk Management - Integrated Framework. Executive Summary (Tech. Rep.). COSO.

Conforti, R., Fortino, G., Rosa, M. L., \& ter Hofstede, A. H. M. (2011). History-Aware, Real-Time Risk Detection in Business Processes. On the Move to Meaningful Internet Systems: OTM 2011, 100 - 118.

Cope, E. W., Kuster, J. M., Etzweiler, D., \& Deleris, L. A. (2010, Junho). Incorporating risk into business process models. IBM Journal of Research and Development, 54(3), $4: 1-4: 13$.

Davenport, T. (1994). Reengenharia de Processos: como inovar na empresa através da tecnologia da informação (Quinta ed.). Rio de Janeiro: Campus.

Davis, F. D. (1989, Setembro). Perceived Usefulness, Perceived Ease Of Use, And User Accep. MIS Quarterly, 13(3), 319 - 340.

Fenz, S., \& Neubauer, T. (2009, Abril). How to determine threat probabilities using ontologies and Bayesian networks. Cyber Security and Information Intelligence Research (69), 1 - 11.

Haggag, M. H., Khedr2, A. E., \& Montasser, H. S. (2015, Abril). A Risk-Aware Business Process Management Reference Model and Its Application in an Egyptian University. International Journal of Computer Science \& Engineering Survey (IJCSES), 6(2), $11-27$.

Hammer, Michael (2010). What is Business Process Management? In: Brocke, J. \& Rosemann, M. (2010). Handbook on Business Process Management 1: Introduction, Methods, and Information Systems (p. 3-16). Heidelberg, Berlin: Springer.

Hevner, A. R., March, S. T., Park, J., \& Ram, S. (2004, Março). Design Science in Information Systems Research. MIS Quarterly, 28(1), 75 - 105.

Instituto Brasileiro de Governança Corporativa. (2007). Guia de Orientação para Gerenciamento de Riscos Corporativos (Tech. Rep.). São Paulo: Instituto Brasileiro de Governança Corporativa (IBGC).

Islam, M. M. Z., Bhuiyan, M., Krishna, A., \& Ghose, A. (2009). An Integrated Approach to Managing Business Process Risk Using Rich Organizational Models. In (Vol. 5870, pp. 273 - 285). Vilamoura, Portugal: Springer Berlin Heidelberg.

FERREIRA, F. S.; ALVES, C. F.; CAVALCANTI, R. C.

R-BPM: Uma Metodologia para Gerenciamento de Processos de Negócios Consciente dos Riscos

isys | Revista Brasileira de Sistemas de Informação, Rio de Janeiro, vol. 9, No. 4, pp. 05-37, 2016 
Jallow, A. K., Majeed, B., Vergidis, K., Tiwari, A., \& Roy, R. (207, Janeiro). Operational risk analysis in business processes. BT Technology Journal. Kluwer Academic Publishers-Consultants Bureau, 25(1), 168 - 177.

Jans, M., van der Werf, J. M., Lybaert, N., \& Vanhoof, K. (2011). A business process mining application for internal transaction fraud mitigation. Expert Systems with Applications, 38(10), 13351 - 13359.

Markus, M. L., Majchrzak, A., \& Gasser, L. (2002, Setembro). A Design Theory for Systems that Support Emergent Knowledge Processes. MIS Quarterly, 26(3), 179 212.

Oliveira, L. (2014). EBPM: Uma Metodologia para Gestão de Processos de Negócio (Unpublished master's thesis). Centro de Informática - Universidade Federal de Pernambuco, Recife-PE.

Pries-Heje, J., Baskerville, R., \& Venable, J. R. (2008, Janeiro). Strategies for Design Science Research Evaluation. ECIS 2008 Proceedings.

Project Management Institute (PMI). (2012). A guide to the Project management body of knowledge (PMBOK R Guide) (Tech. Rep.). Newtown Square, Pennsylvania: Project Management Institute, Inc.

Rotaru, K., Wilkin, C., Churilov, L., Neiger, D., \& Ceglowski, A. (2011, Dezembro). Formalizing process-based risk with value-focused process engineering. Information Systems and e-Business Management. Springer Verlag, 9(4), 447 - 474.

Sienou, A., Lamine, F., Pingaud, H., \& Karduck, A. (2010, Abril). Risk driven process engineering in digital ecosystems: Modelling risk. Digital Ecosystems and Technologies. Digital Ecosystems and Technologies (DEST), 2010 4th IEEE International Conference on, 647 - 650 .

Suriadi, S., Weiß, B., Winkelmann, A., ter Hofstede, A. H., Conforti, R., Fidge, C., Wynn, M. (2014, Fevereiro). Current Research in Risk-aware Business Process Management Overview, Comparison, and Gap Analysis. Communications of the Association for Information Systems, CAIS, 34(52).

Weiss, B., \& Winkelmann, A. (2011, Janeiro). Developing a Process-Oriented Notation for Modeling Operational Risks - A Conceptual Metamodel Approach to Operational Risk Management in Knowledge Intensive Business Processes within the Financial Industry. System Sciences (HICSS), 2011 44th Hawaii International Conference on. IEEE, 1 - 10 .

Wickbold, J., Bianchin, L., Lunardi, R., Granville, L., Gaspary, L., \& Bartolini, C. (2011, Setembro). A framework for risk assessment based on analysis of historical information of workflow execution in IT systems. Computer Networks: The International Journal of Computer and Telecommunications Networking, 55(13), $2954-2975$.

YIN, Robert K (2001). Estudo de caso: planejamento e métodos. 2. ed. Porto Alegre: Bookman. 